\title{
LA FORMACIÓ DEL PODER POLÍTIC ALS SEGLES XII-XV \\ I ELS ORÍGENS MEDIEVALS DE L'ESTAT. HISTÒRIA POLÍTICA I HISTÒRIA DEL DRET: BIBLIOGRAFIA RECENT EN LLENGUA FRANCESA
}

$(1984-1994)^{1}$

\author{
MAX TURULl Rubinat \\ Facultat de Dret \\ Universitat de Barcelona
}

Rellençar estudis d'història política podria semblar una opció anacrònica després de l'hegemonia que aquesta història ha tingut durant gairebé un segle $\mathrm{i}$, amb excepcions molt notables i meritòries, dels resultats discutibles que ha obtingut. No obstant això, hi ha motius suficients, tant a escala europea com mundial, per justificar una nova història política que permeti de comprendre millor algunes de les transformacions a que està sotmès el món contemporani.

D'una banda es planteja el problema del paper que ha pres l'Estat en les modernes societats occidentals i del nou rol que, en tot cas, caldria assignar-li. Les condicions històriques que van veure consolidar l'estatliberal o democràtic ja no es donen avui. La mundialització de l'economia construeix un nou marc en el que $l^{\prime}$ estat del segle XIX s' hi troba certament desplaçat. Des d'alguns sectors s'ha parlat d'invasió de la vida privada per

\footnotetext{
'Per a la realització d'aquest treball l'autor ha comptat amb una beca per a la recerca $\mathrm{i}$ ampliació d'estudis a l'estranger atorgada per la Direcció General de Recera del Comissionat per a Universitats i Recerca de la Generalitat de Catalunya (resolució de convocatòria de 14 de març de 1995; DOGC núm. 2028 de 22.3.1995)
}

"Anuario de Estudios Medievales", 25 (1995) 
l'Estat i de divorci entre la societat civil i un Estat que ha desenvolupat algunes de les seves capacitats en excés. Al mateix temps hi ha una marcada tendència ideológica contra un Estat-intervencionista sobretot en el domini económic, però amb efectes en l'organització de la societat. Aquesta concepció d'un estat poc intervencionista l'assumeixen sectors neo-lliberals $i$, en algún cas extrem, $s^{\prime}$ 'arriba a postular la necessària dissolució de $l^{\prime}$ Estat i la seva substitució per una mena d'ens merament gestor. La manca d'estat o l'absència d'actuació d'un estat reduït funcionalment al mínim, seria un mitjà d'acció política, igual que ho és la concepció marxista clássica per qui l'estat fora -mentre no arriba la seva desaparició- un instrument de dominació de classe. Contra l'absentisme de l'estat, i des d'una posició contrària a la neo-lliberal, $s^{\prime}$ ha posat èmfasi en la necessitat de la intervenció de l'estat com factor nivellador de desigualtats i, en definitiva, com element cohesionador de la societat, per bé que l'objecte de cohesió no és el mateix avui que fa cent anys $\mathrm{i}$ els actors socials tampoc no són exactament identificables. Maurice Duverger explicava la doble lógica de l'estat amb la seva claretat habitual: I'Estat és com el deu romà Janus, que té dues cares; és al mateix temps un factor d'integració social i també un poderós instrument de dominació. Sigui la que sigui l'actuació que calgui reservar a l'estat, el cas és que aquesta mena d'estat al que ens referim -per omissió podríem dir que estem parlant de l'Estat-nació, que és el model d'estat que va triomfar a Europa- no és en absolut una categoria universal i absoluta, sinó un mer producte de 1 'occident europeu hereu de la cultura romanocristiana, car la tradició bizantino-ortodoxa havia menat a d'altres formes d'organització. Per tant, això ens condueix no ja només a un problema d'història política sinó a una interrogació sobre la nostra cultura occidental que reclama respostes complexes.

D'una altra banda avui se sent la necessitat de comprendre millor la naturalesa del poder polític i, doncs, els seus orígens. La història política una història política en sentit ampli i globalitzador- pot mostrar-se útil i eficaç per aconseguir-ho. $L$ 'actual model d'organització política de la nostra societat, l'Estat-Nació, que s'ha estès per gairebé tot el món, és un producte històric i per tant objecte d'estudi històric si vol ser entès en totes les seves dimensions. Aquesta necessitat d'estudi és encara més imperiosa des del moment que en algunes parts del món aquest model d'organització no només es mostra ineficaç per a resoldre les necessitats més bàsiques de les poblacions i per a emmarcar la vida de la comunitat, sinó que genera problemes seriosos per al seu desenvolupament futur. En fi: com no recórrer 
a la història política avui quan estem assistint a l'aglomeració d'unitats polítiques preexistents (estats nacionals) en conjunts més amplis (Comunitat Europea); quan assistim a l'expansió d'uns imperis i a la desintegració d'uns altres; quan som testimonis d'un retorn simbòlic $i$ ideològic als precedents $o$ als orígens històrics per part $d^{\prime}$ 'alguns nous (vells) nacionalismes; quan observem un altre retorn als antecedents històrics per justificar alguns fenòmens totalitaris religiosos... L'exacta comprensió d'aquest món canviant exigeix aprofundir la recerca sobre la formació del poder polític en general i sobre les relacions entre poder i dret en particular.

Catalunya hauria de ser especialment sensible a aquesta nova història política. I això per diferents motius, presents i passats. D'una banda per la seva història ancorada en la tradició mediterrània i europea: no es tracta en absolut de buscar en la història models de comportament per al futur, però sí que es tracta de comprendre millor les arrels més profundes i els antecedents culturals d'allò que esdevé avui. D'una altra banda hi ha el procés d'integració de l'Estat espanyol -dels Reis Catòlics a l'actual Constitució de 1978 passant pels borbons i pel constitucionalisme del segle XIX-, en el que Catalunya, com a comunitat política, no ha acabat de trobar una posició còmoda i estable. Evidentment, aquest no és el nostre centre d'interès immediat, però comprendre la naturalesa del poder polític a Catalunya a la baixa edat mitjana ens sembla una necessitat ineludible que només parcialment ha estat assolida. Ultra les diferents nacions que conviuen i han conviscut en l'actual estat espanyol, ultra, doncs, la seva important diversitat cultural, potser caldria afegir-hi, a títol d' hipòtesi, una determinada "especificitat" catalana -respecte de les "especificitats" de Castella i de França- en la concepció i la pràctica del poder polític. Abadal va plantejar el problema amb una gran clarividència en qualificar de "debilitat congènita de l'estructura estatal catalana" el fet que allò que esdevindria Catalunya no es configurés en un regne ni el titular del poder, el comte de Barcelona, fos un rei. Es així que es produí la paradoxa, d'ençà de la unió amb Aragó, que tinguéssim a Catalunya "un rei sense regne i un Principat sense príncep". En el domini jurídic no $s$ 'ha d'oblidar que a Catalunya el dret comú -romà $i$ canònic- va ser utilitzat des de molt aviat. Per tant, es disposava dels instruments més precisos i preciosos per a elaborar un dret públic per a la comunitat política que s'estava construint. La recerca, certament, he estat encetada. A més d'Abadal, i només per citar dos exemples pertanyents a àmbits historiogràfics diferents, Josep Maria Salrach s'hi ha esmerçat amb resultats importants per a l'alta edat mitjana i Aquilino Iglesia ho ha fet a 
partir de plantejar-se la creació del dret, tant a l'alta com a la baixa edat mitjana catalana.

La història del dret i de les institucions ha de participar en aquesta renovació de la història política i en la comprensió del món polític actual per diferents motius. Si estem parlant de la formació del poder polític a l'edat mitjana, dels orígens medievals de la nostra forma d'organització política, cal dir tot seguit que no hi ha teoria política autònoma a l'edat mitjana, en el moment on situem els grans canvis que expliquen el nostre món i en el moment dels orígens de l'Estat. És en la teologia i, molt aviat -i sobre tot-, en el primer àmbit científic que es va autonomitzar de la teologia, el dret, on podem localitzar les teories polítiques de l'època. No només és que a partir del segle XII van ser els juristes els que més influència van tenir en l'organització política de la societat, sinó també que els principals llibres jurídics -el Corpus Iuris Civilis i el Corpus Iuris Canonici- esdevingueren un tresor de models i de conceptes que aquells juristes van adaptar a la societat d'aquell moment. En part, doncs, és des del Dret que podem comprendre allò que anomenem la teoria política medieval. No ha d'estranyar, doncs, que la Història política sigui objecte d'estudi per a la Història del Dret $\mathrm{i}$ també, doncs, que en la història de les idees i del pensament polític també hi intervinguin aquests mateixos historiadors del dret.

El que proposem, en definitiva, és una aproximació veritablement pluridisciplinar al problema que plantegem -cadascú fent la seva feina, però contrastant resultats $i$ sense desconèixer el que fan els altres- $i$ en la que hi han de participar diferents disciplines: filosofia (política i jurídica), història (de les institucions, de l'art, de la cultura, ...), dret (història del dret), ciència política (bé com a ciència del poder o bé com a ciència de l'estat), sociologia, antropologia, etc. Quan parlem d'història política no pensem, en absolut, en compartimentar més i més la història, fins arribar a un punt que el concepte estigui buit de contingut. El que proposem és just el contrari: que historiadors -i no només historiadors-, amb centres $d^{\prime}$ interès $i$ amb formacions científiques o acadèmiques diferents, col.laborin i participin en un projecte comú. Hom es qüestiona si les administracions competents en política científica no haurien d'impulsar, en l'àmbit de les ciències socials i humanes, un projecte d'aquesta mena -tal com ha estat fet a França fa uns anys des del CNRS- que permetria, ultra l'enorme dispersió en l'actual recerca històrica, d'avançar substancialment en el coneixement i la comprensió del passat medieval. 
El periode objecte d'estudi en una recerca sobre la formació del poder polític podria està fixat entre els segles XII i XV. El segle XII perquè comença a ser sensible la influència del dret romà i canònic redescobert a Bolonya i perquè és l'època -amb la traducció llatina de La Política d'Aristòtil a mitjan segle XIII- que les idees polítiques són especialment fecundes, sense oblidar, no obstant, la tradició visigoda heretada amb el Liber iudiciorum. Al segle XV tot un seguit de canvis substancials en la naturalesa i en l'exercici del poder ja apareixeran ben consolidats. Aquest periode, identificat com a baixa edat mitjana, és una època $d$ 'esclat polític com palesa bé el nou vocabulari dels documents de l'època: és un nou vocabulari jurídic amb mots carregats de sentit $i$ amb una molt forta càrrega política. Els regnes $s^{\prime}$ independitzen de $1^{\prime}$ Imperi germànic -procés en el qual la influència del papat $\mathrm{i}$ del dret canònic són essencials-, però també reivindiquen llur independència de les pretensions universalistes de l'església. Tot això no és només una situació de fet, sinó que va generar una literatura polèmica molt rica $\mathrm{i}$ interessant que actuà alhora de causa $\mathrm{i}$ d'efecte. Els reis reclamen i proclamen la sobirania a 1 'interior dels seus regnes. Primer ho faran des de la mateixa lògica feudal, situant-se al cim de la piràmide senyorial, però més tard consideraran que estaven per damunt $\mathrm{i}$, doncs, per fora $\mathrm{d}^{\prime}$ aquesta jerarquia. També la naturalesa del poder canvia: ja no s'entén la tasca reial com una funció ministerial segons que $s^{\top}$ havia fixat en la tradició carolíngia. La noció aristotèlica de comunitat política natural, transmesa per Sant Tomàs, i l'atribució de la creació del dret en el Princeps -en definitiva en aquesta mateixa comunitat-, com postula el dret romà, suposa, tot això, un canvi notable respecte la tradició altomedieval. Aquest esclat polític anirà acompanyat d'una despersonalització del poder que anirà seguida, paradoxalment, $d^{\prime}$ un enfortiment de la figura del rei com a governant -la noció de corona- i de les seves capacitats polítiques. $S^{\prime}$ ha dit que el nou dret romà-canònic, reelaborat pels juristes bolonyesos, invaeix la societat. Efectivament, aquests juristes construiran jurídicament el món que els envolta i serviran els interessos del poder reial amb una eficàcia desconeguda fins aleshores. Es el dret romà el responsable de la deriva absolutista que prendran algunes monarquies europees a partir del segle $\mathrm{XV}$ ?, o és la manipulació i l'utilització sectària que en van fer alguns legistes al servei del rei? El que sí sembla clar és que al segle $\mathrm{XV}$, i en alguns regnes abans, el rei podrà proclamar i actuar la plena potestat. Com 
tot fenomen de poder, un aparell ideològic entra en escena per a legitimar la titularitat i l'exercici del poder per part del rei. No sembla exagerat parlar d'una religió o d'una ideologia monàrquica que pretén la cohesió de la comunitat al voltant de la figura reial. En aquest sentit, Bernard Guenée escrivia, el 1967, que a Franca l'estat -el rei- havia creat la nació, la qual esdevenia, alhora, el seu millor suport.

Aquest plantejament general podria concretar-se en un seguit d'estudis específics portant sobre les expressions del vocabulari políticojurídic; la noció de sobirania; la utilització del dret feudal en la construcció del nou poder polític baix-medieval; la noció de corona; la influència del dret canònic en la formació del dret públic; les relacions entre dret romà i absolutisme polític i legislatiu; la religió i la legitimació del poder polític; la formació d'una ideologia comunitària (pre-nacional) i la noció i la forma de la llei i la potestat legislativa.

França i Gran Bretanya són els dos països europeus on els estudis recents d'història política i d'història de l'estat han tingut una embranzida més notable en quantitat i qualitat. En el nostre cas ens interessa l'experiència francesa per dos motius. $D^{\prime}$ una banda perquè no $s^{\prime}$ ha $d^{\prime}$ oblidar que allò que un dia va ser la "Catalunya Vella" va formar part de l'imperi de Carlemagne i va rebre, doncs, molt directament la influència carolíngia amb el que això suposa de models de relació amb l'església, amb la noblesa i la concepció, en definitiva, del poder. I d'una altra banda, França va ser -al nord amb retard respecte del Midi- país de dret romano-canònic, el qual va intervenir poderosament -encara que no de manera exclussiva- en la formació del poder polític i en la formació d'un dret públic de la res publica. Les relacions culturals amb França no es van interrompre a l'edat mitjana, ans al contrari. Després de Bolonya, un dels destins preferits dels estudiants catalans va ser Paris per a estudiar-hi teologia i filosofia i Montpeller per a estudiar-hi dret. En fi, la proximitat geogràfica i cultural ha fet que les influències franceses -a banda, evidentment, de les italianes- hagin estat més sensibles que les d'altres cultures.

En la renovació dels estudis polítics a França n'és en bona mesura responsable el projecte de recerca de gran abast llençat des del Centre National de la Recherche Scientifique i del que Jean-Philippe Genet, de la universitat Paris-Sorbona, en fou un dels principals coordinadors. 
Efectivament, el CNRS va organitzar de 1985 a 1988 una Action Thématique Programmée titulada Genèse de l'Etat Moderne. L'objectiu d'aquesta acció era afavorir una nova pràctica de la història política per tal de reinserir-la en els corrents més dinàmics de la recerca a França i per tal de contribuir a crear les condicions d una nova comprensió del passat polític d'Europa en una perspectiva cronològica de llarga durada. El tema estava centrat, formalment, en l'emergència dels "estats monàrquics" entre els anys 1280-1360 i la seva evolució fins el segle XVII. El nucli central del projecte, doncs, implicava totes les formes d'organització i d'exercici del poder polític dins $\mathrm{d}^{\prime}$ aquell marc cronològic.

D'altra banda, els treballs preparatoris de l'Action Thématique Programmée, van mostrar l'interès i la utilitat d'una aproximació global $\mathrm{i}$ plurisdisciplinar del fenomen polític. És així que es va fixar l'atenció dels següents temes: història del dret; institucions i administració; història de les doctrines polítiques; descobriment, construcció i control de l'espai; desenvolupament $d$ 'una fiscalitat d'Estat; relacions entre estats en temps de guerra i de pau; pràctiques culturals; propaganda i ideologia; relacions entre poders (papat i esglésies). Ultra aquests centres d'interès aparentment tan dispars, el programa també es fixà uns objectius metodològics: facilitar una aproximació plurisdisciplinar al problema plantejat (història, ciències jurídiques, ciències polítiques, antropologia, lingüística, història de l'art, filosofia); afavorir els estudis comparatius i facilitar les col-laboracions internacionals; encarar-se amb fenòmens de llarga durada; i permetre la realització d'instruments de treball.

Aquest programa francès va ser aturat, per raons pressupostàries, $l^{\prime}$ any 1986. Fins aleshores, no obstant, $s$ 'havien presentat 39 projectes de treball dels que en van ser aprovats 24. El mateix any 1986 la European Science Foundation va prendre el relleu al projecte del CNRS i va programar la continuació de la línia de treball que s'havia iniciat a França i que tan bons resultats estava donant. Es programava un nou projecte de recerca europeu per als anys 1988-1992 sota el títol The Origin of the Modern State i els resultats que està previst de publicar -onze obres col.lectives- no són menys interessants. Tant en un cas com en l'altre els grups s'havien constituït amb una ampla participació internacional, especialment amb investigadors francesos, britànics, italians i alemanys. Aquesta mateixa diversitat es reflectia en els nivells de direcció i de coordinació científica.

Malgrat el nivell assolit de la major part de la historiografia jurídica catalana i malgrat $l^{\prime}$ enorme riquesa dels fons medievals conservats en els 
nostres arxius, tret $\mathrm{d}^{\circ}$ algun cas aillat, els investigadors catalans -historiadors i historiadors del dret-, no vàrem participar en aquest important projecte europeu. Avui, no només els resultats científics del projecte europeu no poden ser desconeguts, sinó que és imprescindible de conèixer-los, de servirnos-en i d'entrar en contacte amb els principals protagonistes d'aquestes línies de treball si no volem quedar arraconats dels grans projectes europeus en el terreny, secularment desatès i excessivament compartimentat, de les ciències històrico-jurídiques.

\section{LA BIBLIOGRAFIA QUE PRESENTEM}

Algunes precisions han de ser fetes a propòsit de la bibliografia que presentem. Com es podrà veure, no ens hem cenyit a la bibliografía produïda en el marc de l'esmentat projecte del CNRS francés, ja que malgrat l'impuls important que aquest ha donat a la història política $i$, en menor mesura, a la història jurídica, un bon nombre d'investigadors hi ha treballat al marge. Això no obstant, hem pres la data inicial de 1984 perquè fou la del llençament del projecte del CNRS i perquè 1984-1994 semblava un període suficient de temps per conèixer la producció historiográfica veïna. Les edicions de l'any 1995 també han estatincloses en la mesura que n' hem pogut tenir coneixement directe.

D'altra banda, si bé els treballs resultants de $1^{\prime}$ Action Thématique Programée francesa són inclosos en la present bibliografia, no podem dir el mateix dels resultants de l'acció menada per la European Science Foundation, ja que la major part dels volums són actualment en premsa. Està prevista, però, l'aparició de deu volums col.lectius, el títol provisional dels quals podem avançar per gentilesa del professor Jean-Philippe Genet. Set volums col.lectius provenen dels grups de treball temàtics creats en el marc del projecte: Philippe CONTAMINE (ed.), War and Competition between States; Richard BONNEY (ed.), Economic systems and state finance; A. PADOA SCHIOPA (ed.), Legislation and Justice. Legal instruments of Power; Wolfgang REINHARD (ed.), Elites and State Building in Europe (13th-18th centuries); Peter BLICKLE (ed.), Resistance, Representation and sense of Community; Janet Coleman (ed.), The Individual in Political Theory and Practice; Allan ElleniUs (ed.), Iconography, Propraganda and Legitimation. Tres altres volums són el fruit de conferències organitzades pel mateix programa: Wim BLOCKMANS et Jean-Philippe GENET (ed.), Visions sur le 
développement des Etats Européens. Théories et historiographies de l'Etat Moderne (ja publicat i buidat en la nostra bibliografia); Jean-Philippe GENET et Günther LOTTES (ed.), L'Etat moderne et les élites; apports et Limites de la méthode prosopographique; Wim BLOCKMANS, Jorge BORGES DE MACEDO, Jean-Philippe GENET (eds.), The Heritage of the Pre-Industrial State. Els set primers volums, que apareixeran en anglès, estant sent traduïts al francés i es preveu una eventual traducció al castellà per Fondo de Cultura Económica i a l'alemany. La provisionalitat dels treballs que conté cada volum ens aconsella de no donar-ne els títols.

La present bibliografia no és exhaustiva, ni quantitativament ni qualitativament: en el primer sentit perquè no hem inclòs absolutament tot el que s'ha publicat des de 1984 i en el segon sentit perquè la línia divisòria entre allò que entrava $i$ allò que no entrava en el nostre centre $d$ 'interès orígens de $1^{\prime}$ estat $\mathrm{i}$ formació del poder polític-, no era nítida ni clara; per tant, en aquest sentit, el criteri del compilador ha actuat en última instància, encara que hem intentat aplicar un criteri extensiu més que no restrictiu. El criteri central de la selecció que presentem és triple, havent de reunir en cada cas totes tres condicions: a) havia de tractar-se de treballs d'història "general" i d'història del dret versant directament o indirecta sobre els orígens de l'estat i la formació del poder polític a França o a Europa en general; b) havien de ser treballs publicats en llengua francesa; c) havien de ser treballs sobre el període medieval, des de Clovis fins el final del segle

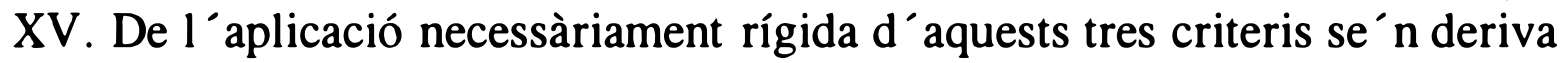
que no hem inclòs algunes aportacions en llengua francesa sobre diferents regnes hispànics -pensem en treballs de Martí Aurell, Bartolomé Benassar, Pablo Fernández Albaladejo, Paul Freedman, Miguel Angel Ladero Quedada, Béatrice Leroy, Adeline Rucquoi, Ludwig Vones i Michel Zimmermann entre d'altres-, ni tampoc aportacions en llengua castellana sobre regnes hispànics en publicacions franceses. Aquesta bibliografia hispànica, $d^{\prime}$ 'altra banda, és de més fàcil accès $i$ coneixença, per bé que hi hem deixat la referència bibliogràfica bàsica quan es tractava d'obres col-lectives. Seguint el mateix criteri tampoc no hem inclòs alguns interessants treballs sobre $1^{\prime}$ Imperi germànic medieval ni sobre les experiències pre-estatals d'alguns països mediterranis i de $\mathrm{l}^{\prime}$ Europa oriental. De forma sistemàtica no han estat incloses memòries de DEA, de DESS, de $1^{\prime}$ Ecole des Chartes, ni tesis de doctorat (d'Estat o d'universitat) si no estaven publicades. L'abast cronològic ha estat fixat des dels plantejaments de la major part de l'historiografia -general, però també jurídica- francesa, que 
considera Clovis -rei dels francs des del 481- si no el creador de 1' "estat", sí una fita original, de vegades sobretot ideològica, no defugible. Començar a partir de l'adveniment d'Hug Capet, al final del segle X, el 987, no ens hauria permès $d$ 'incloure els estudis sobre el període carolingi que considerem especialment interessants, encara que bona part d'ells es trobin en llengua alemanya $i$ anglesa. Per bé que hem intentat conèixer de primera mà la major part de les referències que incloem, això no sempre ha estat possible; en tot cas hem contrastat les informacions sospitoses a partir de diferents fonts. Per a facilitar una eventual selecció d'obres adquiribles per particulars, departaments o biblioteques, hem indicat sempre que ha estat possible la col.lecció i l'editorial. Així mateix hem inclòs en una secció a part la referència bibliogràfica bàsica completa de les obres col.lectives a les que remeten nombroses entrades, on el títol de l'obra col.lectiva en la que $\mathrm{s}^{\prime}$ inclou un treball apareix en la seva versió més curta.

Amb el desig que aquesta bibliografia esdevingui un instrument pràctic, hem inclòs algunes adreces que poden ser útils: Editions du CNRS (Centre National de la Recherche Scientifique), 20-22 rue Saint-Armand, 75015-Paris; Publications de l'Ecole Française de Rome, Piazza Navona, 62, 00186-Roma; Bibliographie en langue française $d$ 'histoire du droit, Mme. M. Boulet-Sautel, Université Panthéon-Assas, 12 place du Panthéon, 75005-Paris; Presses de l'Ecole Normale Supérieure, 45 rue d'Ulm, 75230Paris cedex 5; PUF (Presses Universitaires de France), librairie génerale et vente par correspondance, 49 boulevard Saint-Michel, 75005-Paris, telf. 43258340, fax 43546481; La boutique de 1'Histoire, 24 rue des Ecoles, 75005-Paris, telf. 46340336, fax 43268396; LGDJ (Librairie Générale de Droit et de Jurisprudence) \& Montchrestien, 20 rue Soufflot, 75005-Paris, telf. 46338985 , fax 40518185 . A més a més són d'una gran utilitat les bases de dades presentades i adquiribles en format CD-ROM, Myriade i Quartier Latin (Chadwyck Healey España. c/ Juan Bravo, 18, 2c, 28006-Madrid; telf. 5755597, fax. 5759885). La primera és el catàleg col.lectiu nacional de publicacions en sèrie $\mathrm{i}$ recull totes les publicacions períodiques -franceses $\mathrm{i}$ estrangeres- que poden ser trobades en totes les biblioteques franceses, especificant quines són disponibles a cada biblioteca. La segona base de dades recull el fons bibliogràfic informatitzat -aproximadament des de 1985de tres importants biblioteques del barri llatí: Bibliothèque interuniversitaire Cujas (dret, economia i gestió), Bibliothèque de la Sorbonne (humanitats) i Bibliothèque Sainte-Geneviève (general). 


\section{BIBLIOGRAFIA}

ALLEMAND-GAY, Marie-Thérèse: Le pouvoir des comtes de Bourgogne au XIIIe siècle, Cahiers d'études comtoises, 36, Les Belles Lettres, Paris, 1988, 495 pp.

ALLMAND, Christopher Thomas: La guerre de cent ans: l'Angleterre et la France en guerre (1300-1450), Payot, Paris, 1989 (1 ${ }^{\text {a }}$ edició en anglès, 1988), 284 pp.

AMALVI, Christian: Le baptême de Clovis: heurs et malheurs d'un mythe fondateur de la France contemporaine (1814-1914), "Bibliothèque de I'Ecole des Chartes", 147 (1989), pp. 583-610.

ANTOINE, Michel: Le dur métier de roi: études sur la civilisation politique de la France d'Ancien Régime, Histoires, Presses Universitaires de France, Paris, 1986, 352 pp.

ARABEYRE, Patrick: Un prélat languedocien au milieu du XVe siècle: Bernard de Rosier, archevêque de Toulouse (1400-1475), "Journal des Savants" (1990), pp. 291-326.

ARABEYRE, Patrick: La France et son gouvernement au milieu du XVe siècle d'après Bernard de Rosier, "Bibliothèque de I'Ecole des Chartes", 150 (1992), pp. 245-285.

AURELL, Martin: La vielle et l'épée. Troubadours et politiques en Provence au XIIIe siècle, Aubier-Montaigne, Paris, 1989, 379 pp.

AUTRAND, Françoise: De l'Enfer au Purgatoire: la cour à travers quelques textes français du milieu du XIVe à la fin du XVe siècle, a: Philippe CONTAMINE (Ed.), "L'Etat et les Aristocraties (France, Angleterre, Ecosse) XIIe-XVIle siècle", Paris, 1989, pp. 51-78.
AUTRAND, Françoise: Charles V le Sage, Fayard, Paris, 1994, 909 pp.

AUTRAND, Françoise: La succession à la couronne de France et les ordonnances de 1374, a: Joël BLANCHARD (Ed), "Représentation, pouvoir et royauté à la fin du Moyen Age", Paris, 1995, pp. 25-32.

AUTRAND, Françoise: La force de l'âge: jeunesse et vieillesse au service de l'Etat en France au XIVe et XVe siècles, "Académie des Inscriptions et Belles-Lettres. Comptes rendus des séances" (1985), pp. 206-220.

AUTRAND, Françoise: Charles VI, la folie du roi, Fayard, Paris, 1986, 647 pp.

AUTRAND, Françoise: $Y$ a-t-il une prosopographie de l'Etat médiéval?, a: Françoise AUTRAND (Ed.), "Prosopographie et genèse de I'Etat moderne", Paris, 1986, pp. 13-18.

Aux sources de la gestion publique. Tome 1: enquête lexicographique sur fundus, villa, domus, mansus. Journée d'étude, Lille, Presses Universitaires de Lille, Lille, 1993, 277 pp.

AVRIL, abbé Joseph: La conception du pouvoir politique d'après les écrits de Guillaume Le Maire, évêque d'Angers (1291-1317), a: "Eglises et Pouvoir politique", Angers, 1987. pp. 117-134.

AVRIL, François; GUENEE, Bernard; GOUSSET, Marie-Thérèse.: Les Grandes Chroniques de France. Reproduction intégrale en fac-similé des miniatures de Fourquet. Manuscrit français 6465 de la Bibliothèque national de Paris, Ed. Philippe Lebaud, Paris, 1987, 291 pp. 
BADIE, Bertrand: L'Etat moderne: le point de vue du politologue, a: Noël COULET et Jean-Philippe GENET (Ed.), "L'Etat moderne: le droit, l'espace et les formes de l'état.", Paris, 1990, pp. 211-218.

BALARD, Michel: Etat et colonisation au Moyen Age. Bilan et perspective, a: Jean-Philippe GENET (Ed.), "L'Etat moderne: genèse. Bilans et perspectives", Paris, 1990, pàg. 65-74.

BALDWIN, John W.: Qu'est-ce que les capétiens ont appris des Plantagenêt?, "Cahiers de civilisation médiévale. $\mathrm{Y}$ a-t-il une civilisation du Monde plantagenêt? Colloque, Fontevraud, 1984", 29, 1-2 (1986), pp. 3-14.

BALDWIN, John W. et GASPARRI, Françoise: Les registres de Philippe Auguste, vol. I, Paris, 1992, 606 pp.

BALDWIN, John W.: Le sens de Bouvines, "Cahiers de Civilisation médiévale", 30, 118 (1987), pp. 119-130.

BALDWIN, John W.: Philippe Auguste et son gouvernement. Les fondations du pouvoir royal en France au Moyen Age, Fayard, Paris, 1991 ( $1^{2}$ edició en anglès, 1986), $717 \mathrm{pp}$.

BARBEY, Jean: La formation des coutumes d'hérédité et de masculinité, "Mémoire", 7 (1987), pp. 65-71.

BARBEY, Jean: Le sacre, a: Stéphane RIALS (Dir.), "Le miracle Capétien", Paris, 1987, pp. 79-86.

BARBEY, Jean: Charles $V$ ou le modèle du Roi, "Mémoire", 3 (1985), pp. 3-18.

BARBEY, Jean; BLUCHE, Frédéric et RIALS, Stéphane: Lois fondamentales et succession de France, col. Cahiers D.U.C., 3, Diffusion Université-Culture, Paris, 1984 ( $2^{\text {a }}$ edició revisada i corregida), $46 \mathrm{pp}$.
BARBEY, Jean, vid. HAROUEL, Jean-Louis: Histoire...

BARBEY, Jean: De la gestion du domaine d̀ l'administration du Royaume, a: Stéphane RIALS (Dir.), "Le miracle Capétien", Paris, 1987, pp. 199-207.

BARBEY, Jean: Etre roi. Le roi et son gouvernement en France de Clovis à Louis XVI, Fayard, Paris, 1992, 573 pp.

BARBEY, Jean: Genèse et consécration des lois fondamentales, "Droits, revue française de théorie juridique", 3 (1986), pp. 75-86.

BARNAVI, Elie: Mythes et réalité historique: le cas de la loi salique, "Histoire, économie et société", 3, 3 (1984), pp. 323-337.

BARRET-KRIEGEL, Blandine: Les chemins de l'Etat, Calmann-Lévy, Paris, 1986, 310 pp.

BARRET-KRIEGEL, Blandine: La politique juridique de la monarchie française et les principes de son droit public, a: "Les monarchies", Paris, 1986, pp. 287-306.

BARRET-KRIEGEL, Blandine: L'Etat et les esclaves. Réflexions pour l'histoire des Etats, Petite Bibliothèque Payot, Payot, Paris, 1989, 281 pp.

BARRET-KRIEGEL, Blandine: La politique juridique de la monarchie française, a: Noël COULET et Jean-Philippe GENET (Ed.), "L'Etat moderne: le droit, l'espace et les formes de l'état", Paris, 1990, pp. 91-108.

BARRET-KRIEGEL, Blandine: Les historiens et la monarchie. I: Jean Mabillon; II: La défaite de l'érudition; III: Les académies de l'histoire; IV: La République incertaine, Les Chemins de $I^{\prime}$ Histoire, Presses Universitaires de France, Paris, 1988, 304, 352, 372, 236 pp. respectivament.

BARTHELEMY, Dominique: L'Etat contre le "lignage": un thème à développer dans l'his- 
toire des pouvoirs en France aux XIe, XIle et XIIIe siècles, "Médiévales", 10 (1986), pp. 37-50.

BARTLETT, Robert J.: Technique militaire et pouvoir politique, 900-1300, "Annales. Economies, Sociétés, Civilisations", 41, 5 (1986), pp. 1135-1159.

BASSE, Bernard: La constiturion de l'ancienne France: principes et lois fondamentales de la royauté française, Ed. Martin Morin, Paris, 1986, 392 pp.

BASTIT, Michel: Naissance de la loi moderne. La pensée de la loi de saint Thomas à Suarez, Presses Universitaires de France, Paris, 359 pp.

BATANY, Jean: Les débats des trois états et l'ombre du Prince dans le Songe de Pestilence, a: Joël BLANCHARD (Ed), "Représentation, pouvoir et royauté à la fin du Moyen Age", Paris, 1995, pp. 131-142.

BAUCHY, Jacques-Henri: Orléans et le sacre des Capétiens: chroniques de 987 à 1022, Tours, 1987, $230 \mathrm{pp}$.

BAUTIER, Robert-Henri: La chancellerie carolingienne, "Bibliothèque de I'Ecole des Chartes", 142, 1 (1984), pp. 5-88.

BAUTIER, Robert-Henri: "Empire Plantagenêt" ou "espace Plantagenêt". Y eut-il une civilisation du monde Plantagenêt?, "Cahiers de civilisation médiévale. Actes du colloque du monde Plantagenêt, Fontevraud, 1984", 29 (1986), pp. 139-147.

BAUTIER, Robert-Henri: L'avènement d'Hugues Capet et le sacre de Robert le Pieux, a: PARISSE, Michel et BARRAL I ALTET, Xavier (Etudes réunies par), "Le Roi de France et son royaume autour de l'an Mil", Paris, 1992, pp. 27-37.

BAUTIER, Robert-Henri: Le personnel de la chancellerie royale sous les derniers capétiens, a: Françoise AUTRAND (Ed.), "Prosopographie et genèse de l'Etat moderne", Paris, 1986, pp. 91-116.

BAUTIER, Robert-Henri: Etudes sur la France capétienne, de Louis VI aux fils de Philippe le $\mathrm{Bel}$, Variorum, Londres, 1992, 322 pp. (compilació d'articles).

BAUTIER, Robert-Henri: Contestations de la personne et de l'autorité du Roi (XIIIe-XIVe siècles): l'exemple d'Orléans (1284), a: "Actes du $114 \mathrm{e}$ Congrès National des Sociétés savantes, Paris, 1989. Section d'Histoire médiévale et de philologie: violence et contestation au Moyen Age", Paris, 1990, pp. 207-233.

BAUTIER, Robert-Henri: Sacres et couronnements sous les carolingiens et les premiers capétiens: recherches sur la genèse du sacre royal français, "Annuaire-Bulletin de la Société de l'histoire de France", année 1987-1988, $(=1989)$, pp. 7-56.

BAUTIER, Robert-Henri: Recherches sur l'histoire de la France médiévale, des Mérovingiens aux premiers Capériens, Variorum, Londres, 1991, 332 pp. (compilació d'articles).

BAUTIER, Robert-Henri: Le développement de la centralisation monarchique dans la France du Moyen Age, a: "Centralismo y descentralización. Modelos y procesos históricos en Francia y en España", Madrid, 1985, pp. 179-213.

BAYARD, Jean-Pierre: Sacres et couronnements royaux, Trédaniel, Paris, 1984, 376 pp.

BEAUD, Olivier: La notion d'Etat, "Archives de Philosophie du Droit", 35 (1990), pp. 119-141.

BEAUNE, Colette: Prophétie et propagande: le sacre de Charles VII, a: "Idéologie et propagande en France", 1987, pp. 63-73. 
BEAUNE, Colette: Les théoriciens françaises contestataires du sacre au XVe siècle, a: "Le sacre des rois. Actes du Colloque international d'histoire sur les sacres et couronnements royaux", Paris, 1985, pp. 233-241.

BEAUNE, Colette: Le rêve du roi fondateur dans l'histoire de France, a: "Genèse de I'Etat moderne en Méditerranée. Approches historique et anthropologique des pratiques et des représentations", Rome, 1993, pp. 27-44.

BEAUNE, Colette: La notion de nation en France au Moyen Age, "Communications. Ecole Pratique de Hautes Etudes", 45 (1987), pp. 101-116.

BEAUNE, Colette: Naissance de la nation France, col. Bibliothèque des histoires, édit. Gallimard, Paris, 1985, 431 pp. (també a la col-lecció Folio/histoire 56, Gallimard, Paris, 1985 [=1993], 574 pp.)

BEAUNE, Colette: L'utilisation politique $d u$ mythe des origines troyennes en France à la fin du Moyen Age, a: "Lectures médiévales de Virgile". Rome, 1985, pp. 331-355.

BEAUNE, Colette: Les sanctuaires royaux. De Saint-Denis à Saint-Michel et Saint-Léonard, a: Pierre NORA (Dir.), "Les lieux de mémoire. Tome II: La Nation, 1", Paris, 1986, pp. 57-87.

BEAUNE, Colette: Les capétiens et la naissance d'une histoire nationale, a: Stéphane RIALS (Dir.), "Le miracle Capétien", Paris, 1987, pp. 68-75.

BEAUNE, Colette: Le miroir du pouvoir, col. Banque nationale de Paris, Hervas, Paris, 1989, $188 \mathrm{pp}$.

BEAUNE, Colette: L'historiographie de Charles VII: un thème de l'opposition à Louis $X I$, a: Bernard CHEVALIER et Philippe CONTAMINE (Eds.), "La France de la fin du XVe siècle, renouveau et apogée: économie, pou- voirs, arts, culture et conscience nationales", Paris, 1985, pp. 265-281.

BEDOS, Br.: Signes et insignes du pouvoir royal et seigneurial au Moyen Age: le témoignage des sceaux, a: "Les pouvoirs de commandement jusqu'à 1610. Actes du CVe congrès national des Sociétés Savantes. Caen, 1980, Philologie et Histoire jusqu' à 1610; tome 1", Paris, 1984, pp. 47-62.

BERENGER, Jean et TOLLET, Daniel: La genèse de l'Etat Moderne en Europe orientale. Synthèse et bilan, a: Jean-Philippe GENET (Ed.), "L'Etat moderne: genèse. Bilans et perspectives", Paris, 1990, pp. 43-64.

BERNIER, Robert: L honneur de Dieu et l'honneur du Roi: convergences ou conflits?, "Vu de haut. Institut Universitaire Saint-Pie X", 6, 1987, pp. 11-25.

BESNIER, Robert: Le sacre des rois de Fran$c e$, "Vu de haut. Institut Universitaire Saint-Pie X", 6, 1987, pp. 131-148.

BIGET, Jean-Louis; HERVE, Jean-Claude et THEBERT, Yvon: Expressions iconographiques et monumentales du pouvoir d'Etat en France et en Espagne à la fin du Moyen Age: l'exemple d'Albi et de Grenade, a: "Cu Iture et idéologie dans la genèse de l'Etat moderne", Rome, 1985, pp. 245-279.

BLANCHARD, Joël: Le corps du roi: mélancolie et "recreation". Implications médicales et culturelles du loisir des princes à la fin $d u$ Moyen Age, a: Joël BLANCHARD (Ed), "Représentation, pouvoir et royauté à la fin du Moyen Age", Paris, 1995, pp. 199-211.

BLANCHARD, Joël: L'entrée du poète dans le champ politique au XVe siècle, "Annales. Economies, Sociétés, Civilisations", 41, 1 (1986), pp. 43-61.

BLANCHARD, Joël: Discours de la réformation et utopie à la fin du Moyen Age: le "Songe du Vieil Pèlerin" de Philippe de Mézières 
(1389), "Studi Francesi", 32 (1988), pp. 397-403.

BLOCKMANS, Wim; GENET, Jean-Philippe et MUHLBERG, Christoph: The Origin of the Modern State. Additional activity of the European Science Foudation, a: Jean-Philippe GENET (Ed.), "L'Etat moderne: genèse. Bilans et perspectives", Paris, 1990, pp. 285-304.

BLOCKMANS, Wim: Les origines des Etats modernes en Europe, XIIIT-XVIIIe siècles: état de la question et perspectives, a: Wim BLOCKMANS et Jean-Philippe GENET (Ed.), "Visions sur le développement des Etats européens. Théories et historiographies de l'Etat moderne", Rome, 1993, pp. 1-14.

BLOCKMANS, Wim: Princes conquérants et bourgeois calculateurs. Le poids des réseaux urbains dans la formation des états, a: Neithard BULST et Jean-Philippe GENET (Eds), "La ville, la bourgeoisie et la genèse de l'Etat moderne (XIIe-XVIIIe siècles)", Paris, 1988, pp. 167-181.

BLUCHE, Frédéric, vid. BARBEY, Jean: Lois fondamentales...

BONGERT, Yvonne: L'interdit, arme de l'Eglise contre le pouvoir temporel, a: "Eglises et pouvoir politique", Angers, 1987, pp. 93-116.

BONNEFIN, Aimé: La monarchie française, 987-1789: constitutions, lois fondamentales, France-Empire, Paris, 1987, 398 pp.

BORDONOVE, Georges: Les rois qui ont fait la France: Louis XI, le diplomate, PygmalionGérard Watelet, Paris, 1986, 320 pp.

BORDONOVE, Georges: Les rois qui ont fait la France: Philippe le Bel, roi de fer, Pygmalion-Gérard Watelet, Paris, 1984, 320 pp.
BORDONOVE, Georges: Les rois qui ont fait la France: Hugues Capet, le fondateur, Pygmalion-Gérard Watelet, Paris, 1986, 322 pp.

BORDONOVE, Georges: Les rois qui ont fait la France. Charlemagne. Empereur et Roi, Études historiques, Pygmalion/Gérard Watelet, Paris, 1989, $318 \mathrm{pp}$.

BORDONOVE, Georges: Les rois qui ont fait la France: Saint-Louis, roi éternel, PygmalionGérard Watelet, Paris, 1984, 320 pp.

BORDONOVE, Georges: Les Grandes Heures de l'Histoire de France. Jeanne d'Arc et la Guerre de Cent Ans, Pygmalion/Gérard Watelet, Paris, 1994, 450 pp.

BORDONOVE, Georges: Les rois qui ont fait la France. Charles VII, le Victorieux, Études historiques, Pygmalion/Gérard Watelet, Paris, 1985, $318 \mathrm{pp}$.

BORDONOVE, Georges: Les rois qui ont fait la France. Philippe Auguste le Conquérant, Pygmalion-Gérard Watelet, Paris, 1986, 3โ7 $\mathrm{pp}$.

BORDONOVE, Georges: Les rois qui ont fait la France. Clovis et les mérovingiens, Études historiques, Pygmalion/Gérard Watelet, Paris, 1988, $318 \mathrm{pp}$.

BOUARD, Michel de: Guillaume, l'Etat et la Raison d'Erat, "Précis analytique des travaux de l'Académie des sciences, belles lettres et arts de Rouen", 1987, pp. 193-202.

BOUINEAU, Jacques: Histoire des Institutions. Ier.-XVe siècle., Litec, Paris, 1994, 648 pp.

BOULET-SAUTEL, Marguerite; SAUTEL, Gérard; HAROUEL, J.L.; LORGNIER, M.J. et coll.: Bibliographie ell langue française d'histoire du droit Iconcernant l'année 1988, tome $X X X$ ), Université de Paris II. Paris, 1992. $271 \mathrm{pp}$. (darrer volum aparegut). 
BOULET-SAUTEL. Marguerite: Le Roi et l'Eglise, a: Stéphane RIALS (Dır.), "Le miracle Capétien", Paris. 1987. pp. 215-230.

BOULET-SAUTEL, Marguerite: Le Roi et l'Empereur, a: Stéphane RIALS (Dır.), "Le miracle Capétien", Paris, 1987, pp. 63-68.

BOUREAU, Alain: Les cérémonies rovales françaises entre performance juridique et compétence liturgique. "Annales. Economies, Sociétés, Civilisations", 46, 6 (1991), pp. 1253-1264.

BOUREAU, Alain: Pierre et Jean Olivi et l'émergence d'une théorie contractuelle de la royauté au XIIIe siècle, a: Joël BLANCHARD (Ed), "Représentation, pouvorr et royauté à la fin du Moyen Age". Paris, 1995, pp. 165-175.

BOUREAU, Alain: Le Roi, a: Pierre NORA (Dir.), "Les lieux de mémoire. Tome III: Les France, vol. 3", Paris, 1992, pp. 785-817.

BOUREAU, Alain: Le simple corps du Roi. $L$ 'impossible sacralité des souverains français, XVe-XVIIle siècles, Ed. de Paris, Paris, 1988, $155 \mathrm{pp}$.

BOUREAU, Alain: Droit et théologie au Moyen Age, "Annales. Economies, Sociétés, Civilisations", 47, 6 (1992), pp. 1113-1125.

BOUREAU, Alain: Un obstacle à la sacralité royale en Occident: le principe hiérarchique, a: Alain BOUREAU et Claudio Sergio INGERFLOM (Ed.), "La royauté sacrée dans le monde chrétien", Paris, 1992, pp. 29-38.

BOURNAZEL, Eric, vid. HAROUEL, Jean-Louis: Histoire...

BOURNAZEL, Eric, vid. POLY, Jean-Pierre: La mutation...

BOURNAZEL, Eric: Robert, Charles et Dénis: "Le roi de France est empereur en son royaume", a: Jacques KRYNEN et Albert RIGAUDIERE (Dir.), "Droits savants et pratiques françaises du pouvoir (Xle-XVe siècles)". Bordeaux, 1992, pp. 69-77.

BOURNAZEL. Eric: Les étapes de l'implantation royale en Limousin: l'exemple de Saint-Yrieix-la-Perche, "Lemouzi", 115 (1990), pp. 28-34.

BOURNAZEL, Eric: Mémoire et parenté: le problème de la continuité dans la noblesse de l'an Mil, a: Michel PARISSE et Xavier BARRAL I ALTET (Etudes réunies par), "Le roi de France et son royaume autour de l'an mil", Paris, 1992, pp. 111-116.

BOURNAZEL, Eric; VIVIEN, Germain et GOUNELLE, Max: Les grandes dates de l'histoire de France: événements politiques, faits économiques et sociaux, civilisation, Larousse, Paris, 1986, 248 pp.

BOUTET, Didier: Vers l'Etat de droit. La théorie de l'Etat et du droit, Logiques Juridiques, L'Harmattan, Paris, 1991, 271 pp.

BOYER, Jean-Paul: Communautés villageoises et Erat angevin. Une approche au travers de quelques exemples de haute Provence orientale (XIIle-XIVe siècle), a: "Genèse de I'Etat moderne en Méditerrané. Approches historique et anthropologique des pratiques et des représentations", Rome, 1993, pp. 243-265.

BRAUDEL, Fernand: L identité de la France. Espace et Histoire. Tome 1, Arthaud-Flammarion, Paris, 1986, 367 pp.

BRAUNSTEIN, Philippe: Les techniciens et le pouvoir à la fin du Moyen Age: une direction de recherche, a: Françoise AUTRAND (Ed.), "Prosopographie et genèse de I 'Etat moderne", Paris, 1986, pp. 223-230.

BREJON DE LAVERGNEE, Jacques: La permanence de la suzeraineté royale à travers les actes $d$ 'hommages conservés à la chambre des comptes de Paris aux XIVe et Xve siècles pour les pays de Languedoc, a: "La "France 
anglaise" au Moyen Age", Paris, 1988, pp. 259-267.

BRESC, Henri et VEAUVY, Christiane: Genèse de l'Etat moderne en Méditerranée, a: Jean-Philippe GENET (Ed.), "L' Etat moderne: genèse. Bilans et perspectives", Paris, 1990 , pp. 75-94.

BROWN, Elizabeth A.R.: Représentations de la royauté dans les Livres de Fauvel, a: Joël BLANCHARD (Ed), "Représentation, pouvoir et royauté à la fin du Moyen Age", Paris, 1995, pp. 215-235.

BROWN, Elizabeth A.R.: La notion de la légitimité et la prophétie à la cour de Philippe Auguste, a: Elizabeth A.R. Brown, "The Monarchy of Capetian France and Royal Ceremonial", Variorum, London, 1991 (1 $^{\text {a }}$ edició de l'article, 1982), 341 pp.

BRUGUIERE, Marie-Bernadette: Un mythe historique: "l impérialisme capétien" dans le Midi aux XIle et XIIle siècle, "Annales du Midi", 97 (1985), pp. 245-267.

BRUGUIERE, Marie-Bernardette: Autour $d u$ millénaire capétien: indisponibilité de la couronne et liberté individuelle, "Bulletin de I'Association d'entraide de la noblesse française", 193 (1987), pp. 39-46.

BRUGUIERE, Marie-Bernardette: La loi de succession à la couronne de France: naissance d'un droit public et constitutionnel en Europe, "Mémoire", 7 (1987), pp. 73-89.

BRUHL, Carlrichard: Les auto-couronnements d'empereurs et de rois (XIIle-XJXe siècle). Remarques sur la fonction sacramentelle de la royauté au Moyen Age et à l'époque moderne. "Académie des Inscriptions et Belles-Lettres. Comptes rendus des séances" (1984), pp. $102-118$.

BRUHL, Carlrichard: Naissance de deux peuples. Français et Allemands (IXe-XJe siè- cle). Fayard, Paris, 1994 ( $1^{2}$ edició en alemany, 1990), 387 pp.

BRYANT, Lawrence M.: L'entrée royale $\dot{a}$ Paris au Moyen Age. "Annales. Economies, Sociétés, Civilisations", 41, 3 (1986), pp. 513-542.

BUC, Philippe (préface de Jacques Le Goff): L'ambiguité du Livre. Prince, pouvoir, et peuple dans les commentaires de la Bible au Moyen Age. Théologie Historique, 95, Beauchesne, Paris, 1994, XVI+427 pp.

BUC, Philippe: Pouvoir royal et commentaires de la Bible (1150-1350), "Annales. Economies, Sociétés, Civilisations", 44, 3 (1989), pp. 691-713.

BUC, Philippe: Exégèse et pensée politique: Radulphus Niger (vers 1190) et Nicolas de Lyre (vers 1330), a: Joël BLANCHARD (Ed), "Représentation, pouvoir et royauté à la fin du Moyen Age", Paris, 1995, pp. 145-164.

BUHRER-THIERRY, Geneviève: Le conseiller du roi: les écrivains carolingiens et la tradition biblique, "Médiévales", 12 (1987), pp. 111-123.

BULST, Neithard: L'histoire des Assemblées d'états en France et la recherche prosopographique XIVe-milieu XVIIe siècle, a: Françoise AUTRAND (Ed.), "Prosopographie et genèse de I'Etat moderne", Paris, 1986, pp. 171-184.

BULLY, Philippe: Charles VII, le "roi des merveilles", Ed. Tallamandier, Paris, 1994, 339 pp.

BUR, Michel: Adalbéron, archevêque de Reims, reconsidéré, a: Michel PARISSE et Xavier BARRAL I ALTET (Etudes réunies par), "Le roi de France et son royaume autour de I'an mil", Paris, 1992, pp. 55-64.

BUR, Michel: Suger. Abbé de Saint-Denis, régent de France, Librairie Académique Perrin, Paris, 1991, 349 pp. 
CAILLEUX, Philippe: La famille capétienne et l'Erat (Xe-XIVe siècles), "Cité. Revue de la nouvelle citoyenneté". 15 (1987), pp. 25-34.

CARBONELL, Charles-Olivier: Les origines de l'Elat moderne: les traditions historiographiques françaises (1820-1990), a: Wim BLOCKMANS et Jean-Philippe GENET (EN.), "Visions sur le développement des Etats européens. Théories et historiographies de I'Etat moderne", Rome, 1993, pp. 297-312.

CARDOT, Fabienne: L'espace et le pouvoir. Elude sur l'Austrasie mérovingienne, col. Histoire Ancienne et Médiévale, 17, Publications de la Sorbonne, Paris, 1987, 324 pp.

CARON, Marie-Thérèse: Noblesse et pouvoir royal en France. XIIle-XVle siècle. Armand Colin. Paris, 1994, 348 pp.

CARPENTIER, Elisabeth: L'homme, les hommes et la femme. Etude sur le vocabulaire des biographies royales françaises (XIe-XIIIe siècles), "Annales. Economies, Sociétés, Civilisations", 41, 2 (1986), pp. 325-346.

CARPENTIER, E.: Les historiens royaux et le pouvoir capésien: d'Helgaud de Fleury à Guillaume le Breton, a: Jean-Philippe GENET (Ed.), "L'historiographie médiévale en Europe", Paris. 1991, pp. 129-140.

CASSIRER, Emst: Le mythe de l'Etat, Bibliothèque de philosophie, Editions Gallimard, Paris, 1993, 402 pp.

CASTELOT, André: Le domaine des Carolingiens, 768-987, R. Lafont, Paris, 1988, 120 $\mathrm{pp}$.

CLIN, Marie-Véronique, vid. PERNOUD, Régine: Jeanne...

COLLIN, Hubert: Les préparatifs du sacre du roi Charles IV le Bel à la cour comtale de Bar-le-Duc en 1322, a: "Le sacre des rois. Actes du Colloque international d histoire sur les sacres et couronnements royaux", Paris, 1985, pp. 141-144.

CONSTANT, Jean-Marie: Les partis nobiliaires et le développement de l'Etat moderne: le rôle de la noblesse seconde, a: Jean-Philippe GENET (Ed.), "L'Etat moderne: genèse. Bilans et perspectives", Paris, 1990, pp. 175-184.

CONTAMINE, Philippe: Des pouvoirs en France 1300-1500, Presses de I'Ecole Normale Supérieure, Paris, 1992, 270 pp.

CONTAMINE, Philippe: Le vocabulaire politique en France à la fin du Moyen Age: $L$ 'idée de réformation, a: Jean-Philippe GENET et Bernard VINCENT (Eds), "Etat et Eglise dans la genèse de 1'Etat moderne", Madrid, 1986, pp. 145-156.

CONTAMINE, Philippe: La France de la fin du XVe siècle: pour un état des questions, a: "La France de la fin du XVe siècle, renouveau et apogée: économie, pouvoirs, arts, culture et conscience nationales", Paris, 1985, pp. 1-12.

CONTAMINE, Philippe: "Le royaume de France ne peut tomber en fille": fondement, formulation et implication d'une théorie politique à la fin du Moyen Age. "Perspectives médiévales", 13 (Paris, 1987), pp. 67-81.

CONTAMINE, Philippe: Les pairs de France au sacre des rois (XVe siècle): nature et portée d'un programme iconographique, "Bulletin Société Antiq. France" (1988), pp. 321-346.

CONTAMINE, Philippe: Un traité politique inédit de la fin du Xve siècle. "Annuaire-Bulletin de la Société de I'Histoire de France, années 1983-1984", $1986(=1983-1984)$, pp. 139-171.

CONTAMINE, Philippe: La "France anglaise" au Xve siècle. Mythe ou réalité, a: "La "France anglaise" au Moyen Age", Paris, 1988, pp. 17-29. 
CONTAMINE, Philippe: L'Etat et les aristocraties, a: Philippe CONTAMINE (Ed.), " $L$ 'Etat et les Aristocraties (France, Angleterre, Ecosse) XIle-XVII siècle", Paris, 1989. pp. 11-26.

CONTAMINE, Philippe: L'amour de la patrie, "L'Histoire", 96 (1987), pp. 12-18.

CONTAMINE, Philippe: La mémoire de l'Etat: les archives de la Chambre des comptes de France à Paris, au XVe siècle, a: "Media in Francia. Recueil de mélanges offer à Karl Ferdinand Werner", Paris, 1989, pp. 85-100.

CORBIER, Mireille: De la razzia au butin. $\mathrm{Du}$ tribut à l'impôt. Aux origines de la fiscalité: prélèvements tributaires et naissance de l'Etat, a: Jean-Philippe GENET (Ed.), "L'Etat moderne: genèse. Bilans et perspectives", Paris, 1990, pp. 95-108.

COUDERT, Jean: Un miroir de la société mérovingienne: le traité d'Andelot, "Les cahiers haut-marnais", 175 (1988), pp. 1-13.

COUTANT DE SAISSEVAL, Guy: La légitimité monarchique: le droit royal historique, Ed. Christian, Paris, 1985, 208 pp.

COUTEAU-BEGARIE, Hervé: Géopolitique des Capétiens, a: Stéphane RIALS (Dir.), "Le miracle Capétien", Paris, 1987, pp. 115-122.

CHANUT, Christian-Philippe: Louis XVV et le 800e anniversaire d'Hugues Capet, "Mémoire", 7 (1987), pp. 91-97.

CHARTIER, Roger: Construction de l'Etat moderne et formes culturelles: perspectives et questions, a: "Culture et idéologie dans la genèse de l'Etat moderne", Rome, 1985, pp. 491-503.

CHARTRAUB, Fr., vid. DUPUY, Cl.: Traité...
CHASSIGNEUX, Pierre: Le millénaire capétien: 987, la naissance de la France capétienne. "Administration", 137 (1987), pp. 92-98.

CHEVALIER, Bemard: Du droit d'imposer et de sa pratique. Finances et financiers du roi sous le règne de Charles VIII, a: Joël BLAN. CHARD (Ed), "Représentation, pouvoir et royauté à la fin du Moyen Age", Paris, 1995. pp. 33-47.

CHEVALIER, Bernard: Introduction, a: Jean-Philippe GENET (Ed.), "L'Etat moderne: genèse. Bilans et perspectives", Paris, 1990 , pp. 7-16.

CHEVALIER, Bemard: L'Etat et les bonnes villes en France au temps de leur accord parfait (1450-1550), a: Neithard BULST et Jean-Philippe GENET (Eds), "La ville, la bourgeoisie et la genèse de $1^{\circ}$ Etat moderne (XIle-XVIIle siècles)", Paris, 1988, pp. 71-85.

CHIANEA, Gérard: Histoire des institutions publiques de la France. I. Du démembrement à la reconstitution de l'Etat (496-1492), col. Le droit en plus; Presses Universitaires de Grenoble, Grenoble, 1994, 168 pp.

CHIFFOLEAU, Jacques et VINCENT, Bernard: Etat et Eglise dans la genèse de l'Etat Moderne. Premier bilan, a: Jean-Philippe GENET et Bernard VINCENT (Eds), "Etat et Eglise dans la genèse de I'Etat moderne", Madrid, 1986, pp. 295-310. •

CHIFFOLEAU, Jacques: Le crime de majesté médiéval, a: "Genèse de l'Etat moderne en Méditerrané. Approches historique et anthropologique des pratiques et des représentations", Rome, 1993, pp. 183-213.

CHRISTOL, Michel: Prosopographie et Histoire de l'Etat: le cas de l'Empire romain, a: Françoise AUTRAND (Ed.), "Prosopographie et genèse de I'Etat moderne", Paris, 1986, pp. 19-34. 
DAVESNES, Jean-Clair: Le bonheur des Capétiens, Editions Dominique Martin Morin, Bouere, 1987, 268 pp.

DEGUIGNET, Patrick: La survivance de l'idée capétienne sous la République, a: "Les Robertiens-Capétiens du IXe au XXe siècle. Bulletin de la Société historique de Compiègne", 30 (1988), pp. 197-204.

DELORT, Robert: Charlemagne, M.A. Editions, Paris, 1986, 206 pp.

DEMANT, Alain: La politique extérieure des Capétiens: tradition nationale et refus des empires, "Revue Historique", t. 279, 2, n. 566 (1988), pp. 305-311.

DEMOTZ, B.: L'Etat et le château au Moyen Age: l'exemple savoyard, "Journal des Savants" (1987), pp. 27-64.

DEMOUY, Patrick: Reims, ville des sacres capétiens, "Mémoire", 7 (1987), pp. 47-63.

DEMURGER, Alain: L'apport de la prosopographie à l'étude des mécanismes des pouvoirs, XIIle-XVe siècles, a: Françoise AUTRAND (Ed.), "Prosopographie et genèse de l'Etat moderne", Paris, 1986, pp. 289-302.

DEMURGER, Alain: L'action locale des agents du pouvoir central en Normandie (1380-1422), a: "L'administration locale et le pouvoir central en France et en Russie (XIIle-XVe siècles)", Paris, 1990, pp. 56-106.

DEPEYROT, Georges: Production monétaire et Etat: bilan et perspectives, a: Jean-Philippe GENET (Ed.), "L'Etat moderne: genèse. Bilans et perspectives", Paris, 1990, pp. 109-114.

DEPREUX, Philippe: Nithard et la res publica: un regard critique sur le règne de Louis le Pieux, "Médiévales", 22-23 (1992), pp. 149-161.
DEPREUX, Philippe: Saint Rémi et la royauté carolingienne, "Revue Historique", t. 285, 2 , 578 (1991), pp. 235-260.

DEQUEKER-FERGON, Jean-Michel: $L^{\prime} H i s-$ toire au service des pouvoirs: l'assassinat du duc d'Orléans, "Médiévales", 10 (1986), pp. 51-68.

DESOBRY, Jean: Le "miracle" des écrouelles dans l'iconographie régionale, a: "Les Robertiens et Capétiens du IXe au XXe siècle", Compiègne, 1988, pp. 175-196.

DESPORTES, Pierre: Les frais du sacre à Reims aux XIIIe et XIVe siècles, a: "Le sacre des rois. Actes du Colloque international d'histoire sur les sacres et couronnements royaux", Paris, 1985, pp. 145-155.

DEVIOSSE, Jean: Jean le bon, Fayard, Paris, 1985, $552 \mathrm{pp}$.

DUBOUCHET, Paul: La pensée juridique avant et après le code civil, L'Hermès, Lyon, 1994, $3^{\text {a }}$ ed. ( $1^{\text {a }}$ ed. 1991), 492 pp.

DUBREUCQ, A.: Le De institutione regia de Jonas d'Orléans, "L information historique", 55, 2 (1993), pp. 52-56.

DUBY, Georges: Histoire de France Hachette. Le Moyen Age. De Hugues Capet à Jeanne d'Arc 987-1460, Paris, 1987, 357 pp.

DUMONTIER, Michel et GERSAL, Frédérick: Des duchés au royaume, F. Lanore - F. Sorlot, Paris, 1987, 168 pp.

DUPRONT, Alphonse: Sacre, autorité, pouvoir: profil d'anthropologie historique, a: "Le Sacre des Rois. Actes du colloque international $d$ 'histoire sur les sacres et couronnements royaux", Paris, 1985, pp. 315-342.

DUPUY, Cl. et CHARTRAUB, Fr., éd. et trad.: Traité des monnaies de Nicolas Oresme et autres écrits monétaires du XIVe siècle (Jean Buridan, Bartolo de Sassoferrato), col. I'his- 
toire partagée, La Manufacture, Lyon, 1989, $206 \mathrm{pp}$.

EHLERS, Joachim: Carolingiens, Robertiens, Ottoniens: politique familiale ou relations franco-allemandes, a: PARISSE, Michel et BARRAL I ALTET, Xavier (Etudes réunies par), "Le Roi de France et son royaume autour de I'an Mil", Paris, 1992, pp. 39-45.

EHLERS, Joachim: La monarchie capétienne et la genèse de la nation française, a: "Pouvoirs et libertés au temps des premiers Capétiens", 1992, pp. 63-78.

EHLERS, Joachim: $L$ 'image de la monarchie française dans l'historiographie de l'Empire (Xe et Xle siècles), a: Jean-Philippe GENET (Ed.), "L historiographie médiévale en Europe", Paris, 1991, pp. 119-128.

ELLUL, Jacques: Le rôle du droit comme réducteur de crise au XIVe siècle, a: "Droit, institutions et systèmes politiques. Mélanges en hommage à Maurice Duverger", Paris, 1987 . pp. 63-77.

ELLUL, Jacques: Remarques sur les origines de l'Etat, "Droits. Revue française de théorie juridique", 15 (1992), pp. 11-17.

FAGNEN, Claude: Le vocabulaire du pouvoir dans les actes de Richard Coeur de Lion, duc de Normandie (1189-1199), "Bulletin philologique et historique du Comité des Travaux historiques et philologiques", I, (1980 [ =1984]), pp. 79-93.

FALKOWSKI, Wojcieh: Contra legem sibi elegerunt: les principes régissant l'exercice du pouvoir royal sous le règne de Charles III le Simple, "Cahiers Civilisation médiévale", 35, 3 (1992), pp. 227-239.

FAVIER, Jean: Dictionnaire de la France Médiévale, Fayard, Paris, 1993, 982 pp.

FEENSTRA, Robert: L'Ecole du droit d'Orléans au XIIIe siècle; un état de la question, a
Aquilino IGLESIA FERREIROS (Ed.), "El Dret Comú i Catalunya. Actes del Ier Simposi Internacional", Fundació Noguera, Barcelona, 1991, pp. 285-307.

FEFFER, Laure-Charlotte et PERIN, Patrick: Aux origines du royaume de France: la Neustrie de Dagobert à Charles le Chauve, "Archeologia", 214 (1986), pp. 22-35.

FEFFER, Laure-Charlotte, vid. PERIN, Patrick: Les Francs...

FERY-HUE, F.: Le cérémonial du couronnement des ducs de Bretagne au XVe siècle. Edition, a: "Questions d'histoire de Bretagne. Actes du CVIIe Congrès national des Sociétés savantes, Brest, 1982. Philologie et Histoire jusqu 'à 1610; tome 2", Paris, 1984, pp. 247-263.

FOGEL, Michèle: L'Etat dans la France moderne de la fin du XVe siècle au milieu du XVIIIle siècle, Hachette, Paris, 1992, 189 pp.

FOSSIER, François: Rapports Eglise Etat. Le Grand Schisme vu par les historiens du XIVe au XVIIe siècle, a: Jean-Philippe GENET et Bernard VINCENT (Eds), "Etat et Eglise dans la genèse de l'Etat moderne", Madrid, 1986, pp. 23-30.

FOSSIER, Robert: Les pouvoirs de commandement sur les personnes et sur les biens, "Bulletin Philologique et Historique du Comité des Travaux historiques et philologiques", I, (1980 [= 1984]), pp. 7-16.

FOULECHAT, Dénis (édition critique avec introduction, notes et glossaire par Charles Brucker): Le Policratique de Jean de Salisbury (1372). Livres I-III, Publications Romanes et Françaises, Librairie Droz, Genève, 1994, 449 pp.

FOVIAUX, Jacques: Comment évêques et moines, détenant l'armée, la justice et les finances ont transmis l'autorité au "Dux" devenu Roi, "Les Robertiens-Capétiens du IXe 
au XXe siècle. Bulletin de la Société historique de Compiègne ", 30, 1988, pp. 95-110.

FOYER, Jean: Introduction au thème, a: "Eglises et pouvoir politique", Angers, 1987, pp. 9-28.

FREUND, Julien: L'essence du politique, Philosophie politique, Sirey, Paris, 1986, 828 pp.

FROMENTOUX, Michel: $l l$ y a mille ans était sacré Robert le Pieux, "Itinéraires, chroniques et documents (Paris)", 319 (1988), pp. 69-79.

GABORIT-CHOPIN, Danielle: Regalia: les instruments du sacre des rois de France, les "Honneurs de Charlemagne", Ed. de la Réunion des Musées nationaux, Paris, 1987, 128 pp.

GARRISSON, Janine: Le Midi est-il français?, "L'Histoire", 96 (1987), pp. 70-75.

GASPARRI, Françoise, vid. BALDWIN, John $\mathrm{W} .:$ Les registres...

GAUDEMET, Jean: Projet d'enquête sur la contribution des juristes médiévaux à la formation de la doctrine de l'Etat moderne, a: Noël COULET et Jean-Philippe GENET (Ed.), "L'Etat moderne: le droit, l'espace et les formes de l'état", Paris, 1990, pp. 85-90.

GAUDEMET, Jean: La Bible dans les collections canoniques, a: Pierre RICHE et Guy LOBRICHON (Dirs.), "Le Moyen Age et la Bible", Paris, 1984, pp. 237-369.

GAUDEMET, Jean: Un point de rencontre entre les pouvoirs politiques et l'Eglise: le choix des évêques (schéma pour une enquête), a: Jean-Philippe GENET et Bernard VINCENT (Eds), "Etat et Eglise dans la genèse de l'Etat moderne", Madrid, 1986, pp. 279-294.

GAUDEMET, Jean: Le dossier canonique $d u$ mariage de Philippe Auguste et d'Ingeburge de Danemark (1193-1213), "Revue historique de droit français et étranger", 62, 1 (1984), pp. 15-29.

GAUDEMET, Jean: Quelques opinions des docteurs médiévaux sur le rôle du peuple dans le gouvernement, "Utrumque ius. Collectio pontificiae universitatis lateranensis", 21 (1991), pp. 229-243.

GAUSSIN, Pierre-Roger: Deux formes de monarchie absolue, deux conceptions de la justice: de Charles VII à Louis XI, a: "Le juste et $l^{\prime}$ injuste à la Renaissance et à $l^{\prime}$ âge classique. Actes du Colloque de St. Etienne, avril 1983", St. Etienne, 1986, pp. 93-100.

GAUVARD, Claude: Ordonnance de réforme et pouvoir législatif en France au XIVe siècle, a: André GOURON et Albert RIGAUDIERE (Eds), "Renaissance du pouvoir législatif et genèse de l'Etat", Montpellier, 1988, pp. 89-98.

GAUVARD, Claude: $L$ 'image du roi justicier en France à la fin du Moyen Age, $d$ 'après les lettres de rémission, a: "La faute, la répression et le pardon. Actes du CVIIe Congrès national des Sociétés savantes, Brest, 1982. Philologie et Histoire jusqu'à 1610; tome 1", Paris, 1984, pp. 165-192.

GAUVARD, Claude: Le roi de France et l'opinion publique à l'époque de Charles VI, a: "Culture et idéologie dans la genèse de l'Etat moderne", Rome, 1985, pp. 353-366.

GAZZANIGA, Jean-Louis: Les clercs au service de l'Etat dans la France du XVe siècle. $A$ la lecture de travaux récents, a: Jacques KRYNEN et Albert RIGAUDIERE (Dir.), "Droits savants et pratiques françaises du pouvoir (XIe-XVe siècles)", Bordeaux, 1992, pp. 253-278.

GAZZANIGA, Jean-Louis: Mandat et représentation dans l'Ancien Droit, "Droits. Revue française de théorie juridique", 6 (1987), pp. 21-30. 
GEARY, Patrick J.: Vivre en conflit dans une France sans Etat: typologie des mécanismes de règlement des conflits (1050-1200), "Annales. Economies, Sociétés, Civilisations", 41, 5 (1986), pp. 1107-1133.

GEARY, Patrick J.: Le monde mérovingien. Naissance de la France, col. Histoires, Flammarion, Paris, 1989 ( $1^{\text {a }}$ edició en anglès, 1988), 293 pp.

GENET, Jean-Philippe, vid. BLOCKMANS, Wim: The Origin...

GENET, Jean-Philippe: L'Etat de la fin $d u$ Moyen Age et le concept d'espace économique (France et Angleterre), a: Bernard CHEVALIER et Philippe CONTAMINE, "La France de la fin du XVe siècle, renouveau et apogée: économie, pouvoirs, arts, culture et conscience nationales", Paris, 1985, pp. 31-49.

GENET, Jean-Philippe: L'Etat moderne: un modèle opératoire?, a: Jean-Philippe GENET (Ed.), "L'Etat moderne: genèse. Bilans et perspectives", Paris, 1990, pp. 261-284.

GENET, Jean-Philippe: Prosopographie et genèse de l'Etat moderne, a: Françoise AUTRAND (Ed.), "Prosopographie et genèse de I'Etat moderne", Paris, 1986, pp. 9-12.

GENET, Jean-Philippe: Documents et bibliographie de l'A.T.P. Genèse de l'Etat moderne, a: Jean-Philippe GENET (Ed.), "L'Etat moderne: genèse. Bilans et perspectives", Paris, 1990, pp. 305-350.

GENET, Jean-Philippe: Le médiéviste, la naissance du discours politique et la statistique lexicale:quelques problèmes, a: $\mathrm{C}$. BOURLET et A. DUVOUR (Eds), "L'écrit dans la société médiévale. Divers aspects de sa pratique du XIe au XVe siècle", 1992, pp. 289-298

GENET, Jean-Philippe: L'influence française sur la littérature politique anglaise au temps de la "France anglaise ", a: "La "France anglaise" au Moyen Age", Paris, 1988, pp. 75-90.
GENET, Jean-Philippe: Genèse de l'Etat moderne en Europe, "Le courrier du Centre National de la Recherche Scientifique", 58 (nov-déc. 1984), pp. 32-39.

GENET, Jean-Philippe: L'économie du politique: théologie et droit dans la science politique de l'Etat moderne, a: "Théologie et Droit dans la Science Politique de I'Etat moderne", Rome, 1991, pp. 17-28.

GENET, Jean-Philippe: La typologie de l'Etat moderne, le droit, l'espace, a: Noël COULET et Jean-Philippe GENET (Ed.), "L'Etat moderne: le droit, l'espace et les formes de l'état", Paris, 1990, pp. 7-14.

GENET, Jean-Philippe: Conclusion, a: Wim BLOCKMANS et Jean-Philippe GENET (Ed.), "Visions sur le développement des Etats européens. Théories et historiographies de $1^{\prime}$ Etat moderne", Rome, 1993, pp. 313-321.

GENET, Jean-Philippe: Féodalisme et naissance de l'Etat moderne: à propos des thèses de Charles Tilly, a: Monique BOURIN (éd.), "Villes, bonnes villes, cités et capitales. Etudes $d^{\prime}$ histoire urbaine (XIle-XVIIle siècle) offertes à Bernard Chevalier", Tours, 1989, pp. 239-246.

GENET, Jean-Philippe: Conclusion, a: Neithard BULST et Jean-Philippe GENET (Eds), "La ville, la bourgeoisie et la genèse de I'Etat moderne (XIIe-XVIIle siècles)", Paris, 1988, pp. 339-352.

GENET, Jean-Philippe: Le développement des monarchies d'Occident est-il une consequence de la crise?, a: "Europa en los umbrales de la crisis (1250-1350). XXI Semana de Estudios Medievales. Estella, 18 al 22 de julio de 1994", Gobierno de Navarra; Departamento de Educación y Cultura, Pamplona, 1995, pp. 247-273.

GERSAL, Frédérick, vid. DUMONTIER, Michel: Des duchés... 
GIESEY, Ralph E.: Le roi ne meurt jamais, les obsèques royales dans la France de la Renaissance, col. Nouvelle bibliothèque scientifique, Flamarion, Paris, 1987 ( $1^{\text {a }}$ edició en anglès, 1960), 350 pp.

GIESEY, Ralph E.: Cérémonial et puissance souveraine. France, XVe-XVIIe siècles, Cahiers des annales, 41, Armand Colin, Paris, 1987. $170 \mathrm{pp}$.

GIESEY, Ralph E.: Modèles de pouvoir et rites royaux en France, "Annales. Economies, Sociétés, Civilisations", 41, 3 (1986), pp. 579-599.

GIORDANENGO, Gérard: Les feudistes (XJle$X V e$ s.), a Aquilino IGLESIA FERREIROS (Ed.), "El Dret Comú i Catalunya. Actes del IIon Simposi Internacional", Fundació Noguera, Barcelona, 1992, pp. 67-139.

GIORDANENGO, Gérard: La difficile interprétation des données négatives. Les ordonnances royales sur le droit féodal, a: André GOURON et Albert RIGAUDIERE (Eds), "Renaissance du pouvoir législatif et genèse de $I^{\prime} \mathrm{E}$ tat", Montpellier, 1988, pp. 99-116.

GIORDANENGO, Gérard: Le pouvoir législatif du roi de France (XIe-XIIIe siècles): travaux récents et hypothèses de recherche, "Bibliothèque de I'Ecole des Chartes", 147 (1989), pp. 283-310.

GIORDANENGO, Gérard: Le droit féodal dans les pays de droit écrit: l'exemple de la Provence et du Dauphiné, XIle-début XIVe, Bibliothèque des Ecoles françaises $d{ }^{\prime}$ Athènes et de Rome, 1988, 331 pp.

GIORDANENGO, Gérard: $D u$ droit civil au pouvoir royal: un renversement (XIIe-XVe s.), "Politiques et management public (actes du colloque international de Lyon, déc. 1986: "Public, privé: espaces et gestions")", 5, 1 (mars 1987), pp. 9-25.
GIORDANENGO, Gérard: De la Faculté de Décret aux negocia regis. Une répétition d'Evrard de Trémaugon (Paris, 1371), a: Jacques KRYNEN et Albert RIGAUDIERE (Dir.), "Droits savants et pratiques françaises du pouvoir (XIe-XVe siècles)", Bordeaux, 1992, pp. 211-251.

GIORDANENGO, Gérard: Etat et droit féodal en France (XIIe-XIVe siècles), a: Noël COULET et Jean-Philippe GENET (Ed.), "L'Etat moderne: le droit, l'espace et les formes de l état", Paris, 1990, pp. 61-83.

GIORDANENGO, Gérard: Féodalités et droits savants dans le Midi médiéval, Varionum, 1992 (compilació d’articles ja publicats), XII-338 pp.

GIORDANENGO, Gérard: Les droits savants au moyen Age: textes et doctrines. La recherche en France depuis 1968, "Bibliothèque de I'Ecole des Chartes", 148 (1990), pp. 439-476.

GIORDANENGO, Gérard: Législation pontificale et science politique dans le Speculum doctrinale de Vincent de Beauvais (milieu du XIIIe siècle), a: GUICHARD, P.; LORCIN, M.-T.; POISSON, J.-M. et RUBELLIN, M., "Papauté, Monachisme et Théories politiques", Lyon, 1994, pp. I, 71-78.

GISLAIN., Geoffroy de: $L$ 'association au trône (987-1180), "Revue universelle des faits et des idées" (1987), pp. 3-7.

GODDING, Philippe: Le droit coutumier a-t-il recouru à la fiction?, a: DIEVOET, G. van; GODDING, Ph.; AUWEELE, D. van den, "Langage et droit à travers I' histoire. Réalités et fictions", Leuven-Paris, 1989, pp. 93-105.

GOETZ, Hans-Werner: La paix de Dieu en France autour de l'an Mil: fondements et objectifs, diffusion et participants, a: Michel PARISSE et Xavier BARRAL I ALTET (Etudes réunies par), "Le roi de France et son 
royaume autour de l'an mil", Paris, 1992, pp. 131-145.

GOLVEN: La dévolution de la couronne de France, Ed. Sainte Jeanne d'Arc, Villegeon, 1984, $104 \mathrm{pp}$.

GOUNELLE, Max, vid. BOURNAZEL, Eric: Les grandes dates...

GOURON, André: Un assaut en deux vagues: la diffusion du droit romain dans l'Europe du XIle siècle, a Aquilino IGLESIA FERREIROS (Ed.), "El Dret Comú i Catalunya. Actes del Ier Simposi Internacional", Fundació Noguera, Barcelona, 1991, pp. 47-63.

GOURON, André: Théorie desprésomptions et pouvoir législatif chez les glossateurs, a: Jacques KRYNEN et Albert RIGAUDIERE (Dir.), "Droits savants et pratiques françaises du pouvoir (XIe-XVe siècles)", Bordeaux, 1992, pp. 117-127.

GOURON, André: L'entourage de Louis VII face aux droits savants: Giraud de Bourges et son Ordo, "Bibliothèque de I'Ecole des Chartes", 146, 1 (1988), pp. 5-29.

GOURON, André: Continuité et discontinuité dansl' histoire du législatif médiéval: réflexions sur une recherche collective, a: Jean-Philippe GENET (Ed.), "L'Etat moderne: genèse. Bilans et perspectives", Paris, 1990, pp. 217-226.

GOURON, André: Coutume contre loi chezles premiers glossateurs, a: André GOURON et Albert RIGAUDIERE (Eds), "Renaissance du pouvoir législatif et genèse de I'Etat", Montpellier, 1988, pp. 117-130.

GOURON, André: La double naissance de l'Etat législateur, a: "Théologie et Droit dans la Science Politique de I'Etat moderne", Rome, 1991, pp. 101-114.

GOURON, André: Aux origines médiévales de la maxime "Quod omnes tangit", a: "Histoire du droit social. Mélanges en hommage à Jean Imbert", Paris, 1989, pp. 277-286.

GOURON, André: Ordonnances des Rois de France et Droits savants (XIIIe - XVe siècles), "Académie des Inscriptions et Belles-Lettres. Comptes rendus des séances" (nov.-déc. 1991), pp. 851-865.

GOUSSET, Marie-Thérèse, vid. AVRIL, François: Les Grandes Chroniques...

GRABOÏS, Aryeh: La royauté sacrée au XIIe siècle: manifestation de propagande royale, a: "Idéologie et Propagande en France", 1987. pp. 31-41.

GRABOÏS, Aryeh: Un mythe fondamental de l'histoire de France au Moyen Age: le "roi David" précurseur du "roi très chrétien", "Revue Historique", t. 287, 1, n. 581 (1992), pp. 11-31.

GRAVA, Yves: Pouvoir et administration en Provence (XIVe siècle), a: "L'administration locale et le pouvoir central en France et en Russie (XIIIe-XVe siècles)", Paris, 1990, pp. 27-55.

GRIPPARI, Marie-Noëlle: Le jugement de Dieu ou la mise en jeu du pouvoir, "Revue Historique", t. 278, 2, n. 564 (1987), pp. 281-291.

GRISEL, Catherine: Histoire du duché de Normandie et de son rattachement à la couronne de France, Le Coteau, Horvath, 1988, 191 pp.

GUENEE, Bernard: Les "Grandes Chroniques de France", a: Pierre NORA (Dir.), "Les lieux de mémoire. Tome II. La Nation, 1", Paris, 1986, pp. 189-214.

GUENEE, Bernard: Chancelleries et monastères. La mémoire de la France au Moyen Age, a: Pierre NORA (Dir.), "Les lieux de mémoire. Tome II. La Nation, 1", Paris, 1986, pp. 5-30. 
GUENEE, Bernard: Le roi, ses parents et son royaume en France au XIVe siècle, "Bulletino dell' Istituto Storico Italiano per il Medio Evo e Archivio Muratoriano", 94 (1988), pp. 439-470.

GUENEE, Bernard: Un meurtre, une société. $L$ 'assassinat du duc d'Orléans. 23 novembre 1407, col. Bibliothèque des histoires, Gallimard, Paris, 1992, 350 pp.

GUENEE, Bernard: Conclusion, a: "Les Princes et le pouvoir au Moyen Age. XXIIIe Congrès de la Société des Historiens médiévistes de l'enseignement supérieur, Brest, mai 1992", Paris, 1993, pp. 325-330.

GUENEE, Bernard: Introduction, a: Jean-Philippe GENET (Ed.), "L'historiographie médiévale en Europe", Paris, 1991, pp. 13-20.

GUENEE, Bernard (introduction); publiée en latin et traduite par BELLAGUET, M.L. (1842): Chronique des religieux de Saint-Denis contenant le règne de Charles VI de 1380 à 1422 (volume 1: tomes I et II; vol. 2: tomes III et IV; vol 3: tomes $V$ et VI), Comité des travaux historiques et scientifiques, Paris, 1994, LXXXV + 750 + 791, 775 + 781, 768 +806 pp.

GUENEE, Bernard: Des limites féodales aux frontières politiques, a: Pierre NORA (Dir.), "Les Lieux de mémoire. Tome II. La Nation, 2", Paris, 1986, pp. 11-33.

GUENEE, Bernard: Entre l'Eglise et l'Etat, quatre vies de prélats français $\grave{a}$ la fin $d u$ Moyen Age (XIIle-XVe siècles), col. Bibliothèque des histoires, Gallimard, Paris, $1987,508 \mathrm{pp}$.

GUENEE, Bernard, vid. AVRIL, François: Les Grandes Chroniques...

GUENEE, Bernard: L'âge des personnes authentiques: ceux qui comptent dans la société médiévale sont-ils jeunes ou vieux?, a: Françoise AUTRAND, "Prosopographie et genèse de I'Etat moderne", Paris, 1986, pp. 249-280.
GUENÉE, Bernard: L'Occident aux XIVe et XVe siècles. Les Etats, Nouvelle Clio, Presses Universitaires de France, Paris, 1993, 5 edició posada al dia ( $1^{2}$ ed. 1971), XCIII +338 pp.

GUERREAU, Alain: Organisation et contrôle de l'espace: les rapports de l'Etat et de l'E. glise à la fin du Moyen Age, a: Jean-Philippe GENET et Bernard VINCENT (Eds), "Etat et Eglise dans la genèse de l'Etat moderne", Madrid, 1986, pp. 273-278.

GUERY, Alain: La dualité de toutes les monarchies et la monarchie chrétienne, a: Alain BOUREAU et Claudio Sergio INGERFLOM (Ed.), "La royauté sacrée dans le monde chrétien", Paris, 1992, pp. 39-52.

GUERY, Alain: L'Etat. L'outil du bien commun, a: Pierre NORA (Dir.), "Les lieux de mémoire. Tome III: Les France, vol. 3", Paris, 1992, pp. 819-867.

GUERY, Alain: L'Etat monarchique et la construction de la nation française, "Revue de la Bibliothèque Nationale", 32 (1989), pp. 6-17.

GUERY, Alain: Le roi dépensier. Le don, la contrainte, et l'origine du système financier de la monarchie française d'Ancien Régime, "Annales. Economies, Sociétés, Civilisations", 39, 6 (1984), pp. 1240-1260.

GUERY, Alain: Principe monarchique ou roi très chrétien? Les funérailles du roi de France, "Revue de Synthèse", t. 112, sèr. 4, n. 3-4 (1991), pp. 443-454.

GUILlEMAIN, B.: Papauté d'Avignon et Etat Moderne, a: GUICHARD, P.; LORCIN, M.-T.; POISSON, J.-M. et RUBELLIN, M., "Papauté, Monachisme et Théories politiques", Lyon, 1994, pp. I, 79-88.

GUILLOT, Olivier: Formes, fondements et limites de l'organisation politique en France 
au Xe siècle, a: "Il secolo di ferro. Mito e realtà del sec. X", 1991, t. 1, pp. 57-116.

GUILLOT, Olivier; RIGAUDIERE, Albert; SASSIER, Yves: Pouvoirs et institutions dans la France médiévale. I: Des origines à l'époque féodale; II: Des temps féodaux aux temps de l'Etat, Collection U. Histoire Médiévale, Armand Colin, Paris, 1994, I, 332 pp.; II, 320 pp.

GUILLOT, Olivier: A propos d'une lettre de Fulbert de Chartres à Foulque Nerra: un cas de recours au droit savant avant la lettre?, a: Jacques KRYNEN et Albert RIGAUDIERE (Dir.), "Droits savants et pratiques françaises du pouvoir (XIe-XVe siècles)", Bordeaux, 1992, pp. 15-38.

GUILLOTEL, Hubert: Administration et finances ducales en Bretagne sous le règne de Conan III, "Mémoires de la Société Historique et Archèol. Bretagne", 68 (1991), pp. 19-43.

GUILLOTEL, Hubert: Les premières relations de l'Eglise avec le roi Clovis, "Vu de haut. Institut Universitaire Saint Pie X", 6 (1987), pp. 51-63.

GUYOTJEANNIN, Olivier: Les évêques dans l'entourage royal sous les premiers Capétiens, a: PARISSE, Michel et BARRAL I ALTET, Xavier (Etudes réunies par), "Le Roi de France et son royaume autour de I'an Mil", Paris, 1992, pp. 91-98.

HANLEY, Sarah: Le "Lit de Justice" des Rois de France. L'idéologie constitutionnelle dans la légende, le rituel et le discours, Collection Historique, Aubier, Paris, 1991 ( $1^{\text {a }}$ edició en anglès, 1983), $467 \mathrm{pp}$.

HAROUEL, J.L., vid. BOULET-SAUTEL, Marguerite: Bibliographie...

HAROUEL, Jean-Louis; BARBEY, Jean; BOURNAZEL, Eric; THIBAUT-PAYEN, Jacqueline: Histoire des institutions de l'époque franque à la Révolution, Droit Fondamen-
tal/Droit Politique et théorique, Presses Universitaires de France, Paris, $19935^{2}$ ed. (1 ${ }^{\text {a }}$ ed. 1987), $591 \mathrm{pp}$.

HARSGOR, Mikhaël: Maîtres d'un royaume. Le groupe dirigeant français à la fin du XVe siècle, a: Bernard CHEVALIER et Philippe CONTAMINE (Eds.), "La France de la fin du $X V e$ siècle, renouveau et apogée: économie, pouvoirs, arts, culture et conscience nationales", Paris, 1985, pp. 135-146.

HARSGOR, Mikhaël: Maîtres d'un royaume: le groupe dirigeant français à la fin du XVe siècle, a: "La France de la fin du XVe siècle, renouveau et apogée: économie, pouvoirs, arts, culture et conscience nationales", Paris, 1985, pp. 135-146.

HEBERT, Michel: Les assemblées représentatives et la genèse de l'Etat moderne en Provence (XIIIe-XVe siècle), a: "Genèse de I'Etat moderne en Méditerrané. Approches historique et anthropologique des pratiques et des représentations", Rome, 1993, pp. 267-284.

HERBERT, Michel: Les Etats de Provence et le contrôle de l'impôt (XIVe-XVe s.), "Razo. Cahiers du Centre d'études médiévales de Nice", 9 (1989), pp. 67-77.

HERMANN, Christian: Multinationale Habsbourg et universalisme chrétien, a: Jean-Philippe GENET (Ed.), "L'Etat moderne: genèse. Bilans et perspectives", Paris, 1990, pp. 33-42.

HERVE, Jean-Claude, vid. BIGET, Jean-Louis: Expressions...

HIGOUNET, Charles: $A$ propos de la perception de l'espace au Moyen Age, a: "Media in Francia. Recueil de Mélanges offerts à Karl Ferdinand Werner", Maulévrier, 1989, pp. 257-268.

HILAIRE, Jean: La procédure civile et l'influence de l'Etat: autour de l'appel, a: Jacques KRYNEN et Albert RIGAUDIERE (Dir.), "Droits savants et pratiques françaises du 
pouvoir (XIe-XVe siècles)", Bordeaux, 1992, pp. 151-160.

HILAIRE, Jean: Le Roi et Nous: procédure et genèse de l'Etat aux XIIle et XIVe siecles, "Histoire de la Justice", 5 (1992), pp. 3-18.

HOCQUET, 'Jean-Claude: L'impôt du sel et l'Etat, a: "Le roi, le marchand et le sel", Lille, 1987, pp. 27-49.

HOCQUET, Jean-Claude: L'impôt du sel contre la modernité de l'Etat, a: Jean-Philippe GENET (Ed.), "L'Etat moderne: genèse. Bilans et perspectives", Paris, 1990, pp. 115-136.

HOLLAND, H.: La France à la fin du moyen âge: l'Etat et la nation (bilan de recherches récentes), "Médiévales", 10 (1986), pp. 81 -102.

IMBERT, Jean: Temporel et spirituel sous les Carolingiens, "Vu de haut. Institut Universitaire Saint-Pie X", 6 (1987), pp. 65-74.

IMBERT, Jean: La monarchie absolue des Capétiens, "Institut de France, séance publique des cinq Académies, 27 octobre 1987. L'Institut. Paris", núm. 18 (1988), 10 pp.

IOGNA-PRAT, Dominique: La Croix, le moine et l'Empereur: dévotion à la Croix et théologie politique à Cluny autour de l'An Mil, a: "Haut Moyen Age: culture, éducation et société, études offertes à Pierre Riché", Nanterre, 1990, pp. 449-475.

JACKSON, Richard A.: Vivat rex. Histoire des sacres et couronnements en France, Association des publications près les Universités de Strasbourg, Strasbourg-Paris, 1984 ( $1^{2}$ edició en anglès, 1984), 237 pp.

JACKSON, Richard A.: Le pouvoir monarchique dans la cérémonie du sacre et couronement des rois de France, a: Joël BLANCHARD (Ed), "Représentation, pouvoir et royauté à la fin du Moyen Age", Paris, 1995, pp. 237-251.
JACKSON, Richard A.: Les Ordines du couronnement royaux au Moyen Age, a: "Le Sacre des Rois. Actes du colloque international d'histoire sur les sacres et couronnements royaux", Paris, 1985, pp. 63-74.

JACQUART, Jean: L'image des premiers capétiens dans l'historiographie du XVIe siècle, a: "Les Robertiens et Capétiens du IXe au XXe siècle", Compiègne, 1988, pp. 153-162.

JONES, Michaël: Trahison et idée de lèse-majesté dans la Bretagne du XVe siècle, "Actes du 107e Congrès national des Sociétés Savantes. Philologie et Histoire" I (1984), pp. 91-126.

JONES, Michaël: Le cas des Etats princiers: la Bretagne au Moyen Age, a: Noël COULET et Jean-Philippe GENET (Ed.), "L'Etat moderne: le droit, l'espace et les formes de l'état.", Paris, 1990, pp. 129-142.

JONES, Michaël: Aristocratie, faction et Etat dans la Bretagne du XVe siècle, a: Philippe CONTAMINE (Ed.), "L'Etat et les Aristocraties (France, Angleterre, Ecosse), XIIe-XVIIe siècle", Paris, 1989, pp. 129-160.

JONES, Michaël: "En son habit royal": le duc de Bretagne et son image vers la fin du Moyen Age, a: Joël BLANCHARD (Ed), "Représentation, pouvoir et royauté à la fin du Moyen Age", Paris, 1995, pp. 253-278.

JOUANNA, Arlette: La quête des origines dans l'historiographie française de la fin du $X V e$ et du début du XVIe siècle, a: Bernard CHEVALIER et Philippe CONTAMINE (Eds.), "La France de la fin du XVe siècle, renouveau et apogée: économie, pouvoirs, arts, culture et conscience nationales", Paris, 1985, pp. 301-311.

JULLIEN DE POMMEROL, Marie-Henriette: Textes politiques dans la bibliothèque des Papes d'Avignon, a: Jean-Philippe GENET 
(Ed.), "L'Etat moderne: genèse. Bilans et perspectives", Paris, 1990, pp. 207-216.

JUVENAL DES URSINS, Jean (publiés par P.S.LEWIS): Ecrits politiques de Jean Juvénal des Ursins. Tome 2, C. Klincksieck, Paris, 1985, $450 \mathrm{pp}$.

KAEUPER, Richard W.: Guerre, justice et ordre public. L'Angleterre et la France à la fin du Moyen Age, col. Historique, Aubier, Paris, 1994 ( $1^{\text {a }}$ edició en anglès, 1988), 488 pp.

KANTOROWICZ, Ernst H.: Mourir pour la patrie et autres textes, Pratiques Théoriques, Presses Universitaires de France, Paris, 1984, $141 \mathrm{pp}$. (compilació d'articles, edició i traducció de Laurent Mayali i Anton Schütz; presentació de Pierre Legendre).

KANTOROWICZ, Ernst H.: Les deux corps du roi. Essai sur la théologie politique au moyen âge, nrf, Gallimard, Paris, 1994 (1 ${ }^{2}$ edició en anglès, 1957), 634 pp.

KEATS-ROHAN, K.S.B.: Le problème de la suzeraineté et la lutte pour le pouvoir: la rivalité bretonne et l'état anglo-normand, 1066-1154, "M. Soc. Hist. Archéol. Bretagne", 68 (1991), pp. 45-69.

KERHERVE, J.: L'Etat breton aux XIVe et $X V e$ siècles. Les ducs, l'argent et les hommes (2 vols.), Paris, 1987, 1078 pp.

KERMEN, Dénis, vid. LAUPIES, Frédéric: Premières leçons...

KHACHATURIAN, N.A.: Le dualisme de la structure politique en France aux XIVe et XVe siècles, a: " $L$ 'administration locale et le pouvoir central en France et Russie (XIIIe-XVe siècles)", Paris, 1990, pp. 165-176.

KISCH, Yves De: Bernard Palissy, images archéologiques et littéraires du Roi de la Cour, a: Joël BLANCHARD (Ed), "Représentation, pouvoir et royauté à la fin du Moyen Age", Paris, 1995, pp. 295-311.
KLANICZAY, Gábor: L 'image chevaleresque du saint roi au XIle siècle, a: Alain BOUREAU et Claudio Sergio INGERFLOM (Ed.), "La royauté sacrée dans le monde chrétien", Paris, 1992, pp. 53-62.

KLAPISCH-ZUBER, Christiane: Rituels publics et pouvoird'Etat, a: "Culture et idéologie dans la genèse de l'Etat moderne", Rome, 1985, pp. 135-144.

KRYNEN, Jacques: Genèse de l'Etat et histoire des idées politiques en France à la fin du Moyen Age, a: "Culture et idéologie dans la genèse de l'Etat moderne", Rome, 1985, pp. 395-412. (també a: "Etat et pouvoir. Réception des idéologies dans le Midi. L'Antiquité et les Temps modernes", Aix-en-Provence, 1986, pp. 9-22).

KRYNEN, Jacques: Un exemple de critique médiévale des juristes professionnels: Philippe de Mézières et les gens du Parlement de Paris, a: "Histoire du droit social. Mélanges en hommage à Jean Imbert", Paris, 1989, pp. 87-111.

KRYNEN, Jacques: Un thème médiéval aux origines de l'absolutisme français: "le roi très chrétien", a: J. CI. GALEY, "History and Anthropology", [1987?].

KRYNEN, Jacques: "De nostre certaine science...". Remarques sur l'absolutisme législatif de la monarchie médiévale française, a: André GOURON et Albert RIGAUDIERE (Eds), "Renaissance du pouvoir législatif et genèse de I'Etat", Montpellier, 1988, pp. 131-144.

KRYNEN, Jacques: Droit romain et état monarchique. A propos du cas français, a: Joël BLANCHARD (Ed), "Représentation, pouvoir et royauté à la fin du Moyen Age", Paris, 1995, pp. 13-23.

KRYNEN, Jacques: Entre la reforme et la révolution: Paris, 1356-1358, a: Fréderic BLUCHE et Stéphane RIALS (Dir.), "Les Révolutions françaises: les phénomènes révolu- 
tionnaires en France du Moyen Age à nos jours", Paris, 1989, pp. 87-112.

KRYNEN, Jacques: Les légistes "tyrans de la France"? Le témoignage de Jean Juvénal des Ursins, docteur in utroque, a: Jacques KRYNEN et Albert RIGAUDIERE (Dir.), "Droits savants et pratiques françaises du pouvoir (XIe-XVe siècles)", Bordeaux, 1992, pp. 279-299.

KRYNEN, Jacques: Aristotélisme et réforme de l'Etat, en France au XIVe siècle, a: "Schriften des Historischen Kollegs Kolloquien 21. Das Publikum politischer Theorie im 14. Jahrhundert", Oldenbourg, 1991, pp. 225-236.

KRYNEN, Jacques: L'empire du roi. Idées et croyances politiques en France, XIIIe-XVe siècle, Bibliothèque des histoires, Gallimard, Paris, 1993, 556 pp.

KRYNEN, Jacques: Les légistes "idiots politiques". Sur l'hostilité des théologiens à l'égard des juristes, en France, au temps de Charles $V$, a: "Théologie et Droit dans la science politique de l'Etat moderne", Rome, 1991, pp. 171-198.

KRYNEN, Jacques: "Qu'est-ce qu'une nation"? La réponse médiévale française [a propòsit del llibre de Colette Beaune, Naissance la nation France], "Revue historique de droit français et étranger", 64, 1 (1986), pp. 71-78.

KRYNEN, Jacques: Le roi "Très Chrétien" et le rétablissement de la Pragmatique Sanction. Pour une explication idéologique du Gallicanisme parlementaire et de la politique religieuse de Louis XI, a: "Eglises et pouvoir politique", Angers, 1987, pp. 135-149.

KRYNEN, Jacques: L'encombrante figure $d u$ légiste. Remarques sur la fonction du droit romain dans la genèse de l'Etat, "Le Débat", 74 (1993), pp. 45-53.

KRYNEN, Jacques: Réflexion sur les idées politiques aux états généraux de Tours de
1484, "Revue historique de droit français et étranger", 62, 2 (1984), pp. 183-204.

KRYNEN, Jacques: Avant-propos, a: Jacques KRYNEN et Albert RIGAUDIERE (Dir.), "Droits savants et pratiques françaises du pouvoir (XIe-XVe siècles)", Bordeaux, 1992. pp. 9-14.

KRYNEN, Jacques: La représentation politique dans l'ancienne France: l'expérience des Etats Généraux, "Droits, revue française de théorie juridique", 6 (1987), pp. 31-44.

KRYNEN, Jacques: Sur la culture historique des rois: Louis XI et le "Rosier des guerres", a: Gérard AUBIN (Ed.), "Liber Amicorum. Etudes offertes à Pierre Jaubert", Bordeaux, 1992, pp. 399-409.

KRYNEN, Jacques: "Le mort saisit le vif". Genèse médiévale du principe del'instantanéité de la succession royale française, "Journal des Savantes" (juillet-décembre 1984), pp. 187-221.

LA RONCIERE, Charles M. de: L'Etat moderne: le point de vue de l'historien, a: Noël COULET et Jean-Philippe GENET (Ed.), "L'Etat moderne: le droit, l'espace et les formes de l'état", Paris, 1990, pp. 219-227.

LA SELLE, Xavier de: Droit canonique et religion du prince: du confesseur du roi à la grande aumônerie de France (XIIIe-XVle siècles), "Historiens et Géographes", 341 (1993), pp. 227-234.

LA FRANQUERIE, André de: Ascendances davidiques des rois de France et leur parenté avec Notre-Seigneur Jésus-Christ et la très sainte Vierge Marie et saint Joseph, Ed. Sainte Jeanne d'Arc, Villegenon, 1984, 79 pp.

LABANDE-MAILFERT, Y.: Charles VIII. Le vouloir et la destinée, Fayard, Paris, 1986, 512 pp. 
LALOU, Elisabeth: Les révoltes contre le pouvoir à la fin du XIIIe et au début du XIVe siècle, a: "Actes du 114e Congrès national des Sociétés savantes, Paris, 1989. Section d'Histoire médiévale et de philologie: violence et contestation au Moyen Age", Paris, 1990, pp. 159-183.

LANOE, Guy: Les ordines de couronnement (930-1050), a: PARISSE, Michel et BARRAL I ALTET, Xavier (Etudes réunies par), "Le Roi de France et son royaume autour de l'an Mil", Paris, 1992, pp. 65-72.

LAUPIES, Frédéric et KERMEN, Dénis: Premières leçons sur le pouvoir, Collection Major, Presses Universitaires de France, Paris, 1994, 106 pp.

LAVIALLE, Christian: De la fonction $d u$ territoire et de la domanialité dans la genèse de l'Etat en France sous l'ancien régime, "Droits, revue française de théorie juridique", 15 (1992), pp. 19-31.

LE GOFF, Jacques: Le Moyen Age, a: André BURGUIERE et Jacques REVEL (Dir.), "Histoire de la France", Paris, 1989, pp. 19-180.

LE GOFF, Jacques: Aspects religieux et sacrés de la monarchie française du Xe au XIIIe siècle, a: Alain BOUREAU et Claudio Sergio INGERFLOM (Ed.), "La royauté sacrée dans le monde chrétien", Paris, 1992, pp. 19-28.

LE GOFF, Jacques: Aspect religieux et sacré de la monarchie française du Xe au XIIIe siècle, a: "Pouvoirs et libertés au temps des premiers Capétiens", 1992, pp. 309-322.

LE BOURDELLES, Hubert: La survie de l'idéologie royale et des mythes royaux romains dans le haut Moyen Age, a: "Hommage à R. Chevallier, Caesarodunum", 21 bis, 1986, pp. 175-182.

LE GOFF, Jacques: Histoire médiévale et histoire du droit: un dialogue difficile, a: Paolo
GROSSI (a cura di), "Storia sociale e dimensione giuridica, strumenti d'indagine e ipotesi di lavoro. Atti dell 'incontro di studio (Firenze, 26-27 aprile 1985)", Milan, 1986, pp. 23-63 et 449-453.

LE MENE, Michel: Ville et fiscalité d'état à la fin du Moyen Age. L' exemple d'Angers, a: Monique BOURIN (Ed.), "Villes, bonnes villes, cités et capitales. Etudes d'histoire urbaine (XIle-XVIIle siècle) offertes à Bernard Chevalier", Tours, 1989, pp. 89-104.

LE MENE, Michel: Fiscalité d'Etat et solidarités villageoises, a: "Commerce, finances et société (XIe-XVIe siècles)", Paris, 1993, pp. 287-297.

LE ROY, Yves: La Chronique de Morigny et le sacre de Louis VII: le pouvoir royal vers 1131, "Revue historique de droit français et étranger", 65, 4 (1987), pp. 527-544.

LE ROY LADURIE, Emmanuel: Histoire de France Hachette. L'Etat royal: de Louis XI à Henri IV, 1460-1610, tome 2, Paris, 1987, 357 pp. (col. Pluriel, 8548, Hachette, Paris, 1990, 510 pp.)

LE ROY LADURIE, Emmanuel: L'Etat royal, "Mesure", 1 (1989), pp. 157-162.

LE JAN-HENNEBICQUE, Règine: Dommus, illuster, nobilis: les mutations du pouvoir au Xe siècle, a: "Haut Moyen Age, culture, éducation et société. Etudes offertes à Pierre Riché", La Garenne-Colombes, 1990, pp. 439-448.

LE HETE, Thierry: Les Capétiens: le livre du millénaire, Christian, Paris, 1987, 217 pp.

LE GOFF, Jacques: Reims, ville du sacré, a: Pierre NORA (Dir.), "Les lieux de mémoire. Tome II. La Nation, 1", Paris, 1986, pp. 89-184.

LE GOFF, Jacques: $L$ 'histoire politique est-elle toujours l'épine dorsale de l'Histoire?, a: 
"L’imaginaire médiéval", Paris, 1985 (1 ${ }^{\text {a }}$ edició en anglès, 1971), pp. 333-349.

LE GOFF, Jacques: Portrait du roi idéal, "L'Histoire", 81 (1985), pp. 70-76.

LE GOFF, Jacques: Royauté biblique et idéal monarchique médiéval: saint Louis et Josias, a: "Mélanges en I'Honneur de B. Blumenkranz", 1985, pp. 157-167.

LE ROY LADURIE, Emmanuel: La nature du pouvoir royal, "Cité. Revue de la nouvelle citoyenneté", 11 (1985), pp. 5-12.

LEBIGRE, Arlette: La Justice du Roi. La vie judiciaire dans l'ancienne France, Albin Michel, Paris, 1988, 316 pp.

LECA, Antoine: Institutions Publiques Françaises (avant 1789), Librairie de I'Université et Presses Universitaires d'Aix-Marseille, Aix-en-Provence, 1994, 598 pp.

LECOQ, Anne-Marie: La symbolique de l'Etat. Les images de la monarchie des premiers Valois à Louis XIV, a: Pierre NORA (Dir.), "Les lieux de mémoire. Tome II. La Nation, 2", Paris, 1986, pp. 145-192.

LEGENDRE, Pierre: Ecrits juridiques $d u$ Moyen Age occidental, Varionum, Londres, 1988, 535 pp. (compilació d'articles).

LEGENDRE, Pierre: Le désir politique de Dieu: étude sur les montages de l'Etat et du Droit, Fayard, Paris, 1988, 436 pp.

LEGENDRE, Pierre: L'inestimable objet de la transmission. Etude sur le principe généalogique en Occident, Fayard, Paris, 1985, 408 pp.

LEGUAI, André: Fondements et problèmes du pouvoir royal en France (autour de 1400), "Das spätmittelalterliche Königtum", 1987, pp. 41-57.

LEMARIGNIER, Jean-François: Structures politiques et religieuses dans la France du haut
Moyen Age. Recueil d'articles rassemblés par ses disciples, Publications de l'Université de Rouen, Rouen, 1995, 444 pp.

LESNE-FERRET, Maïté: Les fondements $d u$ pouvoir législatif et statutaire dans les seigneuries méridionales, a: André GOURON et Albert RIGAUDIERE (Eds), "Renaissance du pouvoir législatif et genèse de I'Etat", Montpellier, 1988, pp. 145-154.

LEVIS-MIREPOIX, Antoine de: Philippe le $\mathrm{Bel}$, Les Hommes célèbres, Edito-service, diffusion Guide du disque, Genève, 1984, 287 pp.

LEVRON, Jacques: Les rois de France ne divorcent jamais, Perrin, Paris, 1986, 232 pp.

LEWIS, Peter S.: Pourquoi aurait-on voulu réunir des états généraux, en France, à la fin $d u$ Moyen Age?, a: Joël BLANCHARD (Ed), "Représentation, pouvoir et royauté à la fin du Moyen Age", Paris, 1995, pp. 119-130.

LEWIS, Andrew W.: Observations sur la frontière franco-normande, a: Michel PARISSE et Xavier BARRAL I ALTET (Etudes réunies par), "Le roi de France et son royaume autour de l'an mil", Paris, 1992, pp. 147-156.

LEWIS, Peter S.: La "France anglaise" vue de la France française, a: "La "France anglaise" au Moyen Age", Paris, 1988, pp. 31-39.

LEWIS, Andrew W.: Le sang royal. La famille capétienne et l'Etat. France, Xe-XIVe siècle, Bibliothèque des Histoires, Gallimard, Paris, 1986 ( $1^{\text {a }}$ edició en anglès, 1981$), 436 \mathrm{pp}$.

LEWIS, Andrew W.: Successions ottoniennes et robertiennes: un essai de comparaison, a: PARISSE, Michel et BARRAL I ALTET, Xavier (Etudes réunies par), "Le Roi de France et son royaume autour de I'an Mil", Paris, 1992, pp. 47-53.

LOMBARD-JOURDAN, Anne: Fleur de lis et Oriflamme. Signes célestes du royaume de 
France, Centre National de la Recherche Scientifique, Paris, 1991, 319 pp.

LORGNIER, M.J., vid. BOULET-SAUTEL, Marguerite: Bibliographie...

LOUGNOT, Claude: Cluny: pouvoirs de l'an mil, Ed. du Bien public \& Ed. Errance, Dijon \& Paris, 1987, 262 pp.

LLEWELLYN, Peter: Le contexte romain $d u$ couronnement de Charlemagne: le temps de l'Avent de l'année 800, "Moyen Age", 96, sér. 5, t. 4 (Bruxelles, 1990), pp. 209-225.

MAGER, Wolfang: Res Publica chez les juristes, théologiens et philosophes à la fin du moyen âge: sur l'élaboration d'une notion-clê de la théorie politique moderne, a: "Théologie et Droit dans la Science Politique de $1^{\prime}$ Etat moderne", Rome, 1991, pp. 229-239.

MAGER, Wolfgang: République, "Archives de Philosophie du Droit", 35 (1990), pp. 257-273.

MAGNOU-NORTIER, Elisabeth: Pouvoir, finances et politique des premiers Capétiens, a: "Pouvoirs et libertés au temps des premiers Capétiens", 1992, pp. 125-168.

MAGNOU-NORTIER, Elisabeth et NORTIER, Michel: Une ressource fiscale des premiers Capétiens jusqu' au XIIIe siècle: la taille, a: "Histoire économique et financiè re de la France. Etudes et documents, tome 5", Paris, 1993, pp. 3-35.

MAGNOU-NORTIER, Elisabeth: Lex et consuetudo. Enquête dans les sources législatives carolingiennes, a: "Coutumes et libertés. Actes des Journées internationales de Toulouse, 4-7 juin 1987. Recueils de Mémoires et travaux de la Société d'Histoire du Droit", fasc. 14 (1988), pp. 197-207.

MAGNOU-NORTIER, Elisabeth: Recherches sur la fiscalité foncière durant le Haut Moyen Age: premiers résultats, a: Manuel J. PELAEZ, "Historia económica y de las institucio- nes financieras en Europa. Trabajos en homenaje a Ferran Valls i Taberner", Málaga, 1990 , pp. 3351-3370.

MAGNOU-NORTIER, Elisabeth: Un projet de recherche: la fiscalité en Occident du IVe au XIle siècle, a: "Histoire économique et financière de la France. Etudes et documents, tome 2", Paris, 1990, pp. 387-393.

MAGNOU-NORTIER, Elisabeth: $A$ l'origine de l'essor urbain et villageois: le rôle de la fiscalité et de la paix (XIe-XIIe s.), a: "Les origines des libertés", Rouen, 1990, pp. 143-162.

MAGNOU-NORTIER, Elisabeth: Note sur l'expression "justitiam facere" dans les capitulaires carolingiens, a: "Haut Moyen Age, culture, éducation et société. Etudes offertes à Pierre Riché", La Garenne-Colombes, 1990, pp. 249-264

MAIRE VIGUEUR, Jean-Claude, vid. PIETRI, Charles: Avant-propos..

MANN, Patrice: L'Etat, l'action collective et $l$ 'histoire, "Revue française de sociologie", 26 (1985), pp. 695-712.

MARCHELLO-NIZIA, Christiane: Production littéraire, politique linguistique et pouvoir d'Etat au XIIe siècle dans les pays de langue française, a: "Culture et idéologie dans la genèse de I'Etat moderne", Rome, 1985, pp. 199-210.

MASTIAS, René: A propos des "Lois de l'Empereur", "Doc. pour servir Hist. Dpt. Pyrénées-Atlantiques", 11 (1990), pp. 207-212.

MASTROPAOLO, Alfio: L'Etat ou l'ambiguité. Hypothèses pour une recherche, "Revue Française de Science Politique", 36, 1 (1986), pp. 477-495.

MATTEONI, Olivier: L'image du prince dans la chronique du bon duc Loys de Bourbon: les idées politiques d'une oeuvre historique $d u$ 
XVe siècle, "Cahiers d 'histoire", 36, 3 (1991), pp. 215-239.

MAYALI, Laurent: Mythes et réalité de la renaissance juridique au douzième siècle, a Aquilino IGLESIA FERREIROS (Ed.), "El Dret Comú i Catalunya. Ius proprium - Ius commune a Europa. Actes del IIler Simposi Internacional, Homenatge al professor André Gouron", Fundació Noguera, Barcelona, 1993, pp. 187-202.

MAYALI, Laurent: "Lex Animata", rationalisation du pouvoir politique et science juridique (XIle-XIVe siècles), a: André GOURON et Albert RIGAUDIERE (Eds), "Renaissance du pouvoir législatif et genèse de I Etat", Montpellier, 1988, pp. 155-164.

MAYALI, Laurent: De la juris auctoritas à la legis potestas. Aux origines de l'Etat de droit dans la science juridique médiévale, a: Jacques KRYNEN et Albert RIGAUDIERE (Dir.), "Droits savants et pratiques françaises du pouvoir (XIe-XVe siècles)", Bordeaux, 1992. pp. 129-149.

MENACHE, Sophie: Clément $V$ et le royaume de France. Un nouveau regard, "Revue historique de l'église de France", 74 (1988), pp. 23-38.

MENACHE, Sophie: "Un peuple qui a sa demeure à part". Boniface VIII et le sentiment national français, "Francia. Forschungen zur westeuropäischen Geschichte", 12 (1984), pp. 193-208.

MENACHE, Sophie: Philippe le Bel, genèse d'une image, "Revue Belge de Philologie et d'Histoire", t. 62, núm. 4 (1984), pp. 689-702.

MERAD-BOUCHOUAREB, Elisabeth: Ibn-Khaldoun: Origine et décadence des Etats, "Revue historique de droit français et étranger", 71,4 (1993), pp. 585-594.
MERINDOL, Christian de: Saint-Michel et la monarchie française à la fin du moyen âge dans le conflit franco-anglais, a: "La "France anglaise" au Moyen Age", Paris, 1988, pp. 513-542.

MERINDOL, Christian de: L'imaginaire du pouvoir à la fin du Moyen Age. Les prétentions royales, a: Joël BLANCHARD (Ed), "Représentation, pouvoir et royauté à la fin du Moyen Age", Paris, 1995, pp. 65-92.

MERLETTE, Bernard: La légitimité carolingienne aux premiers siècles capétiens, "Les Robertiens-Capétiens du IXe au XXe siècle, Colloque, Compiègne 1987. Bulletin de la Société Historique de Compiègne", 30, 1988, pp. 75-81.

MESTRE, Jean-Louis: Introduction historique au droit administratif français, Droit fondamental. Droit administratif, Presses Universitaires de France, Paris, 1985, 294 pp.

MEXANDEAU, Louis: Les Capétiens, Marabout Université, 464, Marabout, Paris, 1987. $448 \mathrm{pp}$.

MICHAUD, Claude: L'Europe centrale et le cas hongrois, a: Noël COULET et Jean-Philippe GENET (Ed.), "L'Etat moderne: le droit, l'espace et les formes de l'état", Paris, 1990, pp. 189-207.

MILLET, Hélène: La représentativité, source de la légitimité du concile de Pise (1409), a: "Théologie et droit dans la science politique de I'Etat moderne", Rome, 1991, pp. 241-261.

MILLET, Hélène: La place des clercs dans l'appareil d'Etat en France à la fin du Moyen Age, a: "Etat et Eglise dans la Genèse de I'Etat moderne", Madrid, 1986, pp. 239-248.

MILLET, Hélène: Les chanoines au service de l'Etat: bilan d'une étude comparative, a: Jean-Philippe GENET (Ed.), "L'Etat moderne: genèse. Bilans et perspectives", Paris, 1990 , pp. 137-146. 
MILLET, Hélène et POULLE, E.: Le vote de la soustraction d'obédience en 1398 (Assemblée du clergé de France, Paris, 7 mai - ler août 1398), Centre National de la Recherche Scientifique, Paris, 1988, 320 pp.

MINOIS, Georges: Le confesseur du roi: les directeurs de conscience sous la monarchie française, Nouvelles études historiques, Fayard, Paris, 1988, 556 pp.

MIRABILE, Paul: La loi salique et l'expansion franque: politique et stratégie conscientes ou improvisation barbare?, "Stratégique. Revue trimestrielle de recherches et d'études stratégiques", 30 (1986), pp. 87-108.

MOLLAT DU JOURDIN, M.: Le rôle de la mer dans la formation de l'unité française, "Académie des Inscriptions et Belles-Lettres. Comptes rendus des séances", 1987, pp. 699-708.

MONTAIGU, Henry: La couronne de feu: introduction à la lecture symbolique de l'histoire de France. I: le roi capétien, Dervy-Livres, Paris, 1987, 331 pp.

MOREAU, Pierre-François: Jus, Civitas, Imperium: problèmes de terminologie, a: Noël COULET et Jean-Philippe GENET (Eds.), "L'Etat moderne: le droit, l'espace et les formes de I'Etat", Paris, 1990, pp. 25-31.

MOREL, Henri: L'absolutisme français, procéde-t-il du droit romain?, a: "Mélanges Henri Morel", Aix-Marseille, 1989, pp. 525-543 (també a "Mélanges offerts à Jean Imbert", 1989).

MOREL, Henri: La loi innommée, a: "Etat et pouvoir. La Corse dans la pensée politique", Aix-en-Provence et Marseille, 1985, pp. 29-40.

MOREL, Henri: Mélanges Henri Morel, Histoire des idées politiques, Faculté de Droit et de Science Politique et Centre d Etudes et de Recherches d'histoire des idées politiques, Aix-Marseille, 1989, 676 pp.
MOREL, Henri: Le régime mixte ou l'idéologie du meilleur régime politique, a: "Réflexions idéologiques sur l'Etat, aspects de la penséepolitiqueméditerranéenne ", Aix-en-Provence, 1987, pp. 53-69.

MOREL, Henri: Le rôle des juristes dans la formation de la monarchie capétienne, a: "Actes du VIe Colloque de I'Association Française des Historiens des idées politiques, Rennes, 1988", Presses Universitaires d'AixMarseille, 1989 (també a "Mélanges Henri Morel", Aix-Marseille, 1989, pp. 507-523).

MOUSNIER, Roland: Monarchies et royautés, de la préhistoire à nos jours, col. Pour I'histoire, Librairie Académique Perrin, Paris, 1989, 272 pp.

MOUSNIER, Roland: Le phénomène monarchique dans l'Histoire, "Cité. Revue de la nouvelle citoyenneté", 16 (1987), pp. 11-23.

MUHLBERG, Christoph, vid. BLOCKMANS, Wim: The Origin...

MUHLETHALER, Jean-Claude: Le tyran d̀ table. Intertexualité et référence dans l'invective politique à l'époque de Charles VI, a: Joël BLANCHARD (Ed), "Représentation, pouvoir et royauté à la fin du Moyen Age", Paris, 1995, pp. 49-62.

MUSSET, Lucien: Considérations sur la genèse et le tracé des frontières de la Normandie, a: "Media in Francia. Recueil de Mélanges offerts à Karl Ferdinand Werner", Maulévrier, 1989, pp. 309-319.

MUSSOT-GOULARD, Renée: Le gouvernement royal de Hugues Capet, "Mémoire", 7 (1987), pp. 29-45.

MUSSOT-GOULARD, Renée: La naissance de la France, Ed. Perrin, Paris, 1995, 253 pp.

MUSSOT-GOULARD, Renée: La France carolingienne (843-987), Que sais-je?, Presses Universitaires de France, Paris, 1988, 127 pp. 
NICOLET, Claude: Centralisation d'Etat et problème du recensement dans le monde gréco-romain, a: "Culture et idéologie dans la genèse de l'Etat moderne", Rome, 1985, pp. 9-24.

NICOLET, Claude: $L$ 'Empire romain est-il un "Etat moderne"?, a: Noël COULET et Jean-Philippe GENET (Ed.), "L'Etat moderne: le droit, l'espace et les formes de l'état", Paris, 1990, pp. 111-127.

NICOLET, Claude: Rome et les conceptions de l'Etat en France et en Allemagne au XIXe siècle, a: Wim BLOCKMANS et Jean-Philippe GENET (Ed.), "Visions sur le développement des Etats européens. Théories et historiographies de l'Etat moderne", Rome, 1993, pp. 17-44.

NORDMAN, Daniel et REVEL, Jacques: La formation de l'espace français, a: André BURGUIERE et Jacques REVEL (Dir.), "Histoire de la France. L'espace français", Paris, 1989, pp. 33-169.

NORDMAN, Daniel: La connaissance géographique de l'Etat (XIVe-XVIIe siècles), a: Noël COULET et Jean-Philippe GENET (Ed.), "L'Etat moderne: le droit, l'espace et les formes de l'état", Paris, 1990, pp. 175-188.

NORTIER, Michel, vid. MAGNOU-NORTIER, Elisabeth: Une ressource...

OLLAND, Hélène: La France de la fin $d u$ Moyen Age: l'Etat et la nation (bilan de recherches récentes), "Médiévales", 10 (1986), pp. 81-102.

OURLIAC, Paul: Le pouvoir et le droit en Bigorre au XJe siècles, a: Jacques KRYNEN et Albert RIGAUDIERE (Dir.), "Droits savants et pratiques françaises du pouvoir (XIe-XVe siècles)", Bordeaux, 1992, pp. 99-116.

OURLIAC, Paul: Histoire nouvelle et histoire du droit (A propos d'un livre récent), "Revue historique de droit français et étranger", 70, 3 (1992), pp. 363-371.

OURLIAC, Paul: La nation et l'Etat dans l'oeuvre de Guillaume Benoît, canoniste (1455-1516), a: GUICHARD, P.; LORCIN, M.-T.; POISSON, J.-M. et RUBELLIN, M., "Papauté, Monachisme et Théories politiques", Lyon, 1994, pp. I, 147-160.

OURLIAC, Paul: Les pays de Garonne vers l'an Mil. La société et le droit, recueil d'études, Société internationale de l'Histoire de la Profession d'Avocat, Toulouse, 1993, 296 pp.

OURY, Raymond: Introduction au Moyen Age politique ou l'Europe carolingienne, "Recherches médiévales", 34-35 (1991), pp. 37-47.

PACAUT, Marcel: La Théocratie. L'Eglise et le pouvoir au Moyen Age, col. Bibliothèque d'Histoire du Christianisme, 20, Ed. Desclée, Paris, 1989 (nova edició refosa i posada al dia; 1ªdició 1957), 197 pp.

PARISSE, Michel: Hugues Capet et la France de l'an mil, une réhabilitation, "Académie des inscriptions et Belles-Lettres. Comptes Rendus des séances" (1987), pp. 774-785.

PASTOUREAU, Michel: $L$ 'Etat et son image emblématique, a: "Culture et idéologie dans la genèse de l'Etat moderne", Rome, 1985, pp. 145-153.

PASTOUREAU, Michel: Le roi des lis: emblèmes dynastiques et symboles royaux, a: Martine DALAS, "Corpus des sceaux français du Moyen Age. Tome 2: les sceaux des rois et de régence", Paris, 1991, pp. 35-48.

PASTOUREAU, Michel: Images du pouvoir et pouvoir des princes, a: Jean-Philippe GENET (Ed.), "L'Etat moderne: genèse. Bilans et perspectives", Paris, 1990, pp. 227-234.

PASTOUREAU, Michel: Genèse du drapeau. Etats, couleurs et acculturation emblématique autour de la Méditerranée, a: "Genèse de 
l'Etat moderne en Méditerranée. Approches historique et anthropologique des pratiques et des représentations", Rome, 1993, pp. 97-108.

PELIKAN, Jaroslav: La tradition chrétienne. Histoire du développement de la doctrine. I: $L$ 'émergence de la tradition chrétienne, 100-600; II: L'esprit du christianisme 600-1700; III. Croissance de la théologie médiévale, 600-1300; IV. La réforme de l'Eglise et du dogme, 1300-1700; V. Doctrine chrétienne et culture moderne depuis 1700, Théologiques, Presses Universitaires de France, Paris, 1994 ( $1^{\text {a }}$ edició en anglès, 1974-1989), I: XXXII +413; II: XXXVI+360; III: XXXIV + 350; IV: LXIV + 424; V: LXIX+362 pp.

PERIN, Patrick; FEFFER, Laure-Charlotte: Les Francs. Tome 1: à la conquête de la Gaule. Tome 2: à l'origine de la France, Armand Colin, Paris, 1987, 229 pp. (cada tom).

PERIN, Patrick, vid. FEFFER, Laure-Charlotte: Aux origines...

PERIN, Patrick: Clovis et la naissance de la France, Denöel, Paris, 1990, 126 pp.

PERNOUD, Régine et CLIN, Marie-Véronique: Jeanne d'Arc, Fayard, Paris, 1986 [=1987], 447 pp.,

PETIT-RENAUD, Sophie: Le pouvoirnormatif royal, fin XIIIe début XIVe siècles, Paris, 1990. $91 \mathrm{pp}$.

PEYREBONNE, Micheline: La véritable histoire de la loi salique. T. 2: Charles de France et de Navarre et les rois Valois, Europe notre Patrie, Paris, 1992, 215 pp.

PEYVEL, P.: Structures féodales et frontières médiévales: l'exemple de la zone de contact entre Forez et Bourbonnais aux XIIIe et XIVe siècles, "Le Moyen Age", 93 (1987), pp. 51-83.

PIETRI, Charles et MAIRE VIGUEUR, JeanClaude: Avant-propos, a: "Culture et idéologie dans la genèse de l'Etat moderne", Rome, 1985, pp. I-V.

PINOTEAU, Hervé: Les insignes du pouvoir en France, a: "Le sacre des rois. Actes du Colloque international $d$ ' histoire sur les sacres et couronnements royaux", Paris, 1985, pp. 75-83.

PINOTEAU, Hervé: Les insignes du pouvoir des Capétiens directs, "Itinéraires", 323 (1988), pp. 40-54.

PINOTEAU, Hervé: Les insignes du roi vers $l^{\prime}$ an Mil, a: PARISSE, Michel et BARRAL I ALTET, Xavier (Etudes réunies par), "Le Roi de France et son royaume autour de l'an Mil", Paris, 1992, pp. 73-88.

PLATELLE, Henri: Des principautés à l'Empire de Charles-Quint (900-1519), Histoire des provinces françaises du Nord, 2, Ed. des beffrois, Dunkerque, 1989, 279 pp.

POGNON, Edmond: Hugues Capet, qui t'a fait roi?, Stock, Paris, 1987, 233 pp.

POGNON, Edmond: Hugues Capet et la France féodal, L'Histoire de France, Denoël, Paris, 1989, 126 pp.

POIREL, Dominique: Philippe le Bel, Librairie Académique Perrin, Paris, 1991, 461 pp.

POLY, Jean-Pierre: Le Capétien thaumaturge: genèse populaire d'un miracle royal, a: "La France de I'an Mil", Paris, 1990, pp. 282-308.

POLY, Jean-Pierre et RICHE, Pierre: La confusion des peuples (Ve-XIe siècle), a: Yves LEQUIN (Dir.), "La mosaïque France. Histoire des étrangers et de l'immigration en France", Paris, 1988, pp. 49-120.

POLY, Jean-Pierre et BOURNAZEL, Eric: La mutation féodale (Xe à XIle siècles), Nouvelle Clio, Presses Universitaires de France, Paris, 
$1991\left(^{2}\right.$ edició revisada $\mathrm{i}$ posada al dia; $1^{2}$ edició, 1980), 535 pp.

POLY, Jean-Pierre: Les "cochonnales de février", fêtes du sexe, canons de l'Eglise et pouvoir royal au VIIle siècle, a: J. POUMAREDE et J.P. ROYER (textes réunis par), "Droit, histoire et sexualité. Colloque de Toulouse de 1986", Lille, 1987, pp. 55-81.

POLY, Jean-Pierre: La corde au cou. Les Francs, la France et la Loi salique, a: "Genèse de l'Etat moderne en Méditerranée. Approches historique et anthropologique des pratiques et des représentations", Rome, 1993, pp. 287-320.

POLY, Jean-Pierre: Les Deux France, a: Yves LEQUIN (Dir.), "La mosaïque France. Histoire des étrangers et de $1^{\prime}$ immigration en France", Paris, 1988, pp. 131-154.

POLY, Jean-Pierre: Le sac de cuir: La crise de l'an mil et la première renaissance du droit romain, a: Jacques KRYNEN et Albert RIGAUDIERE (Dir.), "Droits savants et pratiques françaises du pouvoir (XIe-XVe siècles)", Bordeaux, 1992, pp. 39-68.

POULlE, E., vid. MILlET, Hélène: Le vote...

POUMAREDE, Jacques: Droit commun versus coutume de Toulouse XIIIe - XVIIIe siècles, a Aquilino IGLESIA FERREIROS (Ed.), "El Dret Comú i Catalunya. Actes del IV Simposi Internacional, Homenatge al professor Josep M. Gay Escoda", Fundació Noguera, Barcelona, 1995, pp. 195-214.

POUPARD, cardinal Paul: Saint Louis ou la sainteté dans la condition de roi, "Esprit et Vie", a. 96, sér. 10, 2e partie, núm. 27-28 (1986), pp. 217-220.

QUILLET, Jeannine: Etat et Nation aux XIVe et XVe siècles: remarques doctrinales, "Etat et Nation. Actes du Colloque de Caen de mai
1988. Cahiers de Philosophie politique et juridique", 14 (1988), pp. 69-81.

QUILLET, Jeannine: Charles $V$ le roi lettré. Essai sur la pensée politique d'un règne, Librairie Académique Perrin, Paris, 1984, 368 pp.

QUILLET, Jeannine: Nicole Oresme traducteur d'Aristote, a: Pierre SOUFFRIN (Ed.), "Nicolas Oresme. Tradition et innovation chez un intellectuel du XIVe siècle", Paris, 1988, pp. 81-91.

QUILLET, Jeannine: Tyrannie et tyrannicide dans la pensée politique médiévale tardive (XIVe-XVe siècles), "Cahiers de philosophie politique et juridique. Colloque la Tyrannie, Caen, 1984", 6 (1984), pp. 63-73.

QUILLET, Bernard: Louis XII, Père du Peuple, Fayard, Paris, 1986, 518 pp.

RACINE, Pierre: $L$ 'occident chrétien au XIIIe siècle. Destins du Saint-Empire et de l'Italie, Regards sur I'histoire, Sedes, Paris, 1994, 479 pp.

RAILLAT, Landric: Charles X: le sacre de la dernière chance, O. Orban, Paris, 1991, 345 pp.

RANGEON, François: $L$ 'idéologie de l'intérêt général, Economica, Paris, 1986, 246 pp.

RAYNAUD, Christiane: Images et pouvoirs au Moyen-Age, Le léopard d' or, Paris, 1993, 278 pp.

REVEL, Jacques: La royauté sacrée: éléments pour un débat, a: Alain BOUREAU et Claudio Sergio INGERFLOM (Ed.), "La royauté sacrée dans le monde chrétien", Paris, 1992. pp. 7-18.

REVEL, Jacques, vid. NORDMAN, Daniel: La formation... 
REYNAUD, Marcelle: Foi et politique. Autour de la mort des princes d'Anjou-Provence (env. 1383 - env. 1480), "Provence Historique" (1986), pp. 21-44.

RIALS, Stéphane, vid. BARBEY, Jean: Lois fondamentales...

RIALS, Stéphane: Monarchie et philosophie politique: un essai d'inventaire, "Mémoire", 5 (1986), pp. 15-36.

RICHE, Pierre: Les clercs carolingiens au service du pouvoir, a: "Idéologie et propagande en France", 1987, pp. 11-18.

RICHE, Pierre, vid. POLY, Jean-Pierre: La confusion...

RIGAUDIERE, Albert: Conclusions, a: Jacques KRYNEN et Albert RIGAUDIERE (Dir.), "Droits savants et pratiques françaises du pouvoir (XIe-XVe siècles)", Bordeaux, 1992, pp. 301-314.

RIGAUDIERE, Albert, vid. GUILLOT, Olivier: Pouvoirs et institutions...

RIGAUDIERE, Albert: Regnum et civitas chez les décrétistes et les premiers décrétalistes (1150 env. -1250 env.), a: "Théologie et droit dans la science politique de l'Etat moderne", Rome, 1991, pp. 117-153.

RIGAUDIERE, Albert: Préface, a: André GOURON et Albert RIGAUDIERE (Eds), "Renaissance du pouvoir législatif et genèse de I'Etat", Montpellier, 1988, pp. 5-11.

RIGAUDIERE, Albert: Princeps legibus solutus est (Dig. I,3,31) et Quod principi placuit legis habet vigorem (Dig. I,4,1 et Inst. I,2,6) à travers trois coutumiers du XIIle siècle, a: "Hommages à Gérard Boulvert", Nice, 1987, pp. 427-451.

RIGAUDIERE, Albert: Loi et état dans la France du bas Moyen Age, a: Noël COULET et Jean-Philippe GENET (Ed.), "L'Etat mo- derne: le droit, l'espace et les formes de l 'état", Paris, 1990, pp. 33-59.

RIGAUDIERE, Albert: Etat, pouvoir et administration dans la Practica aurea libellorum de Pierre Jacobi (vers 1311), a: Jacques KRYNEN et Albert RIGAUDIERE (Dir.), "Droits savants et pratiques françaises du pouvoir (XIe-XVe siècles)", Bordeaux, 1992, pp. 161-210.

RIGAUDIERE, Albert: Gouverner la ville au moyen âge, Historiques, Anthropos, Paris, 1993, 536 pp. (compilació d’articles).

RIGAUDIERE, Albert: Législation royale et construction de l'Etat dans la France du XIIIe siècle, a: André GOURON et Albert RIGAUDIERE (Eds), "Renaissance du pouvoir législatif et genèse de I 'Etat", Montpellier, 1988, pp. 203-236.

RIGAUDIERE, Albert: Réglementation urbaine et législation d'état dans les villes du Midi français aux XIIIe et XIVe siècles, a: Neithard BULST et Jean-Philippe GENET (Eds), "La ville, la bourgeoisie et la genèse de l'Etat moderne (XIle-XVIIle siècles)", Paris, 1988, pp. 35-70.

RIGAUDIERE, Albert: L'invention de la souveraineté, "Pouvoirs. Revue française d'études constitutionnelles et politiques", 67 (1993), pp. 5-20.

RIGAUDIERE, Albert: L'essor de la fiscalité royale, du regne de Philippe le Bel (1285) à celui de Philippe VI (1328-1350), a: "Europa en los umbrales de la crisis (1250-1350). XXI Semana de Estudios Medievales. Estella, 18 al 22 de julio de 1994", Gobierno de Navarra; Departamento de Educación y Cultura, Pamplona, 1995, pp. 323-391.

ROOT, Hilton L.: La construction de l'Etat moderne en Europe. La France et l'Angleterre, Presses Universitaires de France, Paris, 1994, 390 pp. 
ROUX, Jean-Paul: Le roi. Mythes et symboles, Fayard, Paris, 1995, 387 pp.

RUSSO, Daniel: Les modes de représentation du pouvoir en Europe dans l'iconographie du XIVe siècle. Etudes comparées, a: Joël BLANCHARD (Ed), "Représentation, pouvoir et royauté à la fin du Moyen Age", Paris, 1995. pp. 177-198.

SAINSAULIEU, Jean: De Jérusalem à Reims: origines et évolution des sacres royaux, a: "Le sacre des rois. Actes du Colloque international d'histoire sur les sacres et couronnements royaux", Paris, 1985, pp. 17-26.

SANSTERRE, Jean-Marie: $A$ propos des titres d'empereur et de roi dans le haut Moyen Age, "Le souverain à Byzance et en Occident du VIIle au Xe siècle. Byzantion", t. 61, fasc. 1 (1991), pp. 15-43.

SANTINI, Giovanni: Administration publique et droit romain dans la Normandie de Guillaume le Conquérant, "Revue historique de droit français et étranger", 73, 1 (1995), pp. 23-40.

SASSIER, Yves: L'utilisation d'un concept romain aux temps carolingiens: la Res publica aux IXe et Xe siècles, "Médiévales", 15 (1988), pp. 17-29.

SASSIER, Yves: Les progrès de la paix et de la justice du Roi sous le règne de Louis VII, a: G. AUBIN (Ed.), "Liber Amiconum. Etudes offertes à Pierre Jaubert", Bordeaux, 1992, pp. 631-645.

SASSIER, Yves: [L'élection] Au temps de Hugues Capet et des premiers Capétiens, a: L. HAMON et G. LOBRICHON (Eds.), "L'Election du chef de $1^{\circ}$ Etat en France de Hugues Capet à nos jours", Paris, 1988, pp. 25-43.

SASSIER, Yves: Hugues Capet, naissance d'une dynastie, Fayard, Paris, 1987, 357 pp. (també en col-lecció de butxaca, Pluriel H 8521, Fayard, Paris, 1987, 356 pp.)
SASSIER, Yves, vid. GUILLOT, Olivier: Pouvoirs et institutions...

SASSIER, Yves: Louis VII, Fayard, Paris, 1991, $499 \mathrm{pp}$.

SASSIER, Yves: L'utilisation du concept de res publica en France du Nord aux Xe, XIe et XIle siècles, a: Jacques KRYNEN et Albert RIGAUDIERE (Dir.), "Droits savants et pratiques françaises du pouvoir (XIe-XVe siècles)", Bordeaux, 1992, pp. 79-97.

SAUTEL, Gérard, vid. BOULET-SAUTEL, Marguerite: Bibliographie...

SCHMITT, Jean-Claude: Problèmes religieux de la genèse de l'Etat moderne, a: Jean-Philippe GENET et Bernard VINCENT (Eds), "Etat et Eglise dans la genèse de l'Etat moderne", Madrid, 1986, pp. 55-62.

SCHÜTZ, Anton: Saint Augustin, l'Etat et la "bande de brigands", "Droits, revue française de théorie juridique", 16 (1992), pp. 71-82.

SENAC, Philippe: Frontières et espaces pyrénéens au Moyen Age, Université de Perpignan, Perpignan, 1992, 188 pp.

SENELLART, Michel: Les arts de gouverner. Du regimen médiéval au concept de gouvernement, Col. Des travaux, Seuil, Paris, 1995, $311 \mathrm{pp}$.

SENELLART, Michel: Machiavélisme et raison d'Etat. XIIe-XVIIIe siècle, Presses Universitaires de France, Paris, 1989, 127 pp.

SEVE, René: La politique moderne: rupture et continuité, a: "Théologie et Droit dans la Science Politique de l'Etat moderne", Rome, 1991, pp. 63-70.

SIMON, Patrick: Le mythe royal, Aux Amateurs de livres, Paris, 1987, 250 pp.

SIVERY, Gérard: Philippe Auguste, Plon, Paris, 1993, 429 pp. 
SIVERY, Gérard: La description du royaume de France par les conseillers de Philippe Auguste et par leurs successeurs, "Le Moyen Age", t. 90, sèr. 4, t. 39, núm. 1 (1984), pp. 65-85.

SIVERY, Gérard: Blanche de Castille, Fayard, Paris, 1990, 289 pp.

SOT, Michel: Hérédité royale et pouvoir sacré avant 987, "Annales. Economies, Sociétés, Civilisations", 43, 3 (1988), pp. 705-733.

STEGMANN, André: Le Rosier des guerres: testament politique de Louis XI, a: Bernard CHEVALIER et Philippe CONTAMINE (Eds.), "La France de la fin du XVe siècle, renouveau et apogée: économie, pouvoirs, arts, culture et conscience nationales", Paris, 1985, pp. 313-323.

STOCLE, Alain J.: Flores et extracta Vitae Karoli Magni. Une histoire carolingienne dans quelques chroniques universelles des XJe et XIle siècles, "Le Moyen Age", 91 (1985), pp. 357-369.

SUBRENAT, Jean: Un point de vue sur la fonction royale sous Philippe Auguste: le roi Noble dans "Le Roman de Renart", a: "Histoire et société. Mélanges offerts à Georges Duby", 1992, pp. t. 3, 167-177.

SUEUR, Philippe: Histoire du droit public français, XVe-XVIIIe siècles. La genèse de l'Etat contemporaine. T. I: la constitution monarchique; T. 2: affirmation et crise de l'Etat sous l'Ancien Régime, Thémis, Presses Universitaires de France, Paris, 1989, I, 440; II, $601 \mathrm{pp}$.

SUGER (présentation Michel Bur): La Geste de Louis VI, Acteurs de l' histoire, Imprimerie Nationale Editions, Paris, 1994, 302 pp.

TARDITS, Claude: L'Etat moderne: le point de vue de l'anthropologue, a: Noël COULET et Jean-Philippe GENET (Ed.), "L'Etat mo- derne: le droit, l'espace et les formes de l'état", Paris, 1990, pp. 229-233.

TEILLET, S.: Des Goths à la nation gothique. Les origines de l'idée de nation en Occident du Ve au VIIe siècle, Les Belles Lettres, Paris, 1984, $665 \mathrm{pp}$.

THEBERT, Yvon, vid. BIGET, Jean-Louis: Expressions...

THIBAUT-PAYEN, Jacqueline, vid. HAROUEL, Jean-Louis: Histoire...

THIBAUT-PAYEN, Jacqueline: Aux origines de la fortune capétienne: l'héritage mérovingien et carolingien, a: Stéphane RIALS (Dir.), "Le miracle Capétien", Paris, 1987, pp. 29-39.

THOMAS, Yan: $L$ 'empire de la fiction romaine et ses limites médiévales, "Droits. Revue française de théorie juridique", 21 (1995), pp. 17-63.

TIERNEY, Brian: Religion et droit dans le développement de la pensée constitutionnelle (1150-1650), coll. Leviathan, Presses Universitaires de France, Paris, 1993 ( $1^{\text {a }}$ edició en anglès, 1982), $150 \mathrm{pp}$.

TILLY, Charles: Contrainte et capital dans la formation de l'Europe (990-1990), Librairie européenne des idées, Aubier, Paris, 1992 (1 edició en anglès, 1990), 431 pp.

TOLLET, Daniel, vid. BERENGER, Jean: La genèse...

TOUBERT, Pierre: Eglise et Etat au Xle siècle: signification du moment grégorien pour la genèse de l'Etat moderne, a: Jean-Philippe GENET et Bernard VINCENT (Eds), "Etat et Eglise dans la genèse de l'Etat moderne", Madrid, 1986, pp. 9-22.

TRIGEAUD, Jean-Marc: Eléments d'une philosophie politique, Bibliothèque de Philosophie comparée. Philosophie politique, 1, Ed. Biere, Paris, 1993, 282 pp. 
TROUSSET, H.: La légitimité dynastique en France, Roisnart, Grenoble, 1987, 132 pp.

TRUYOL SERRA, Antonio: Souveraineté, "Archives de Philosophie du Droit", 35 (1990), pp. 313-326.

VALENSISE, Marina: Le sacre des rois de France: rituel et politique, "Annales. Economies, Sociétés, Civilisations", 41, 3 (1986), pp. 543-577.

VALLEE, Aline: Etat et sécurité publique au XIVe siecle: une nouvelle lecture des archives royales françaises. A propos de l'inventaire des registres de chancellerie de Philippe IV de Valois, "Histoire, économie et société", 6, 1 (1987), pp. 3-15.

VAN DIVOET, G.: Aristote, la Bible, les chroniques et les coutumiers, sources non juridiques des livres de droit de la fin $d u$ Moyen Age, a: P.L. NEVE et O. MOORMAN VAN KAPPEN (Dir.), "Conservare jura (Journées internationales $d$ 'histoire du droit, Deventer, 1987)", pp. 47-56.

VERDIER, Raymond: De l'histoire du droit a l'histoire des hommes, "Courrier du Centre National de la Recherche Scientifique", 75 (1990).

VERGER, Jacques: Le transfert de modèles d'organisation de l'Eglise à l'Etat à la fin du Moyen Age, a: Jean-Philippe GENET et Bernard VINCENT (Eds), "Etat et Eglise dans la genèse de l'Etat moderne", Madrid, 1986, pp. 31-40.

VERGER, Jacques: Conclusion, a: "Théologie et Droit dans la Science Politique de I'Etat moderne", Rome, 1991, pp. 373-380.

VERGER, Jacques: Conclusion, a: Françoise AUTRAND (Ed.), "Prosopographie et genèse de l'Etat moderne", Paris, 1986, pp. 345-355.

VERNIER, Jean-Marie: Pouvoir temporel et pouvoir spirituel chez Saint Thomas d'Aquin,
"Vu de haut. Institut Universitaire Saint-Pie X", 6 (1987), pp. 27-50.

VERNIER, Jean-Marie: Le droit chez Aristote et Saint Thomas d'Aquin, "Vu de haut. Institut Universitaire Saint-Pie X", 7 (1988), pp. 9-44.

VIDAL, Henri: Le pape législateur de Grégoire VII à Grégoire IX, a: André GOURON et Albert RIGAUDIERE (Eds), "Renaissance du pouvoir législatif et genèse de l'Etat", Montpellier, 1988, pp. 261-275.

VIGUERIE, Jean de: Le sacre des rois de France, "Itinéraires", 319 (1988), pp. 53-68.

VILLEY, Michel: Politique et loi dans la Somme Théologique de Thomas d'Aquin, a: Noël COULET et Jean-Philippe GENET (Ed.), "L'Etat moderne: le droit, l'espace et les formes de l'état", Paris, 1990, pp. 17-24.

VILLEY, Michel: La théologie de Thomas d'Aquin et la formation de l'Etat moderne, a: "Théologie et Droit dans la Science Politique de l'Etat moderne", Rome, 1991, pp. 31-49.

VINCENT, Bernard, vid. CHIFFOLEAU, Jacques: Etat et Eglise...

VIVIEN, Germain, vid. BOURNAZEL, Eric: Les grandes dates...

VLACHOS, Georges: Ce qui est mort et ce qui est vivant dans la Politique d'Aristote, "Revue des sciences morales et politiques" (1984), pp. 287-313.

WERNER, Karl Ferdinand: [Le choix du chef de ['Etat] Avant les Capétiens, a: Léo HAMON et Guy LUBRICHON (Eds.), "L'élection du chef de l'Etat en France de Hugues Capet à nos jours", Paris, 1988, pp. 13-23.

WERNER, Karl Ferdinand: Les femmes, le pouvoir et la transmission du pouvoir, a: "La femme au Moyen Age. colloque international. Maubeuge. 6-9 octobre 1988", Maubeuge, 1990, pp. 365-379. 
WERNER, Karl Ferdinand: Les sources de la légitimité royale à l'avènement des Capétiens (Xe-XJe siècles), a: "Le sacre des rois. Actes du Colloque international $d$ 'histoire sur les sacres et couronnements royaux", Paris, 1985 , pp. 49-60.

WERNER, Karl Ferdinand: Les origines (avant l'an mil), a: Jean Favier (Dir.), "Histoire de France, vol. I", Paris, 1984, 540 pp. (també a: col. Le livre de poche, références, 2936; Edit. Fayard, Paris, 1992, 635 pp.)

WERNER, Karl Ferdinand: Hludovicus Augustus. Gouverner l'empire chrétien: idées et réalités, a: "Charlemagne's heir. New perspectives on the reign of Louis the Pious (814-840)", Oxford, 1990, pp. 3-123.

WERNER, Karl Ferdinand: Les Robertiens, a: PARISSE, Michel et BARRAL I ALTET, Xavier (Etudes réunies par), "Le Roi de France et son royaume autour de I'an Mil", Paris, 1992, pp. 15-26.

WERNER, Karl Ferdinand: Dieu, les rois et l'Histoire, a: "La France de l'an Mil", Paris, 1990, pp. 264-281.

WERNER, Karl Ferdinand: Dieu, le souverain et l'historiographie, "Vu de haut. Institut Universitaire Saint-Pie X", 6 (1987), pp. 75-90.

WERNER, Karl Ferdinand: Royaume et regna. Le pouvoir en France comme enjeu entre le roi et les grands, a: "Pouvoirs et libertés au temps des premiers Capétiens", 1992, pp. 25-62.

WOLFF, Philippe: Hugues Capet et la France méridionale, "Midi", 5 (Toulouse, 1988), pp. 2-8.

WOUW, Hans van de: Quelques remarques sur les versions françaises médiévales des textes de droit romain, a Aquilino IGLESIA FERREIROS (Ed.), "El Dret Comú i Catalunya. Ius proprium - Ius commune a Europa. Actes del IIIer Simposi Internacional, Home- natge al professor André Gouron, Barcelona, 5-7 de novembre de 1992", Fundació Noguera, Barcelona, 1993, pp. 139-148.

ZERNER, Monique: Le comte de Toulouse Raymond IV chef de peuple, a: "Genèse de l'Etat moderne en Méditerranée. Approches historique et anthropologique des pratiques et des représentations", Rome, 1993, pp. 45-60.

ZIMMERMANN, Michel: Les Goths et l'influence gothique dans l'empire carolingien, " $L$ 'art et la société à l'époque carolingien. Cah. St.-Michel de Cuxa", 23 (1992), pp. 31-46.

ZIMMERMANN, Michel (Introd.): Les marches méridionales du royaume aux alentours de l'an Mil: inventaire typologique des sources documentaires, Presses Universitaires de Nancy, Nancy, 1987, 309 pp.

Obres col-lectives (actes de congressos i reunions cientifiques):

Aspects de la vie au XIIIe siècle: histoire, droit, littérature. Actes du Colloque international: Philippe de Beaumanoir et les Coutumes de Beauvaisis (1283-1983), Groupe d'études des Monuments et Oeuvres d'art de Beauvais, Beauvais, 1984, 138 pp.

AUTRAND Françoise (Ed.): Prosopographie et genèse de l'Etat moderne. Actes de la table ronde organisée par le Centre National de la Recherche scientifique et l'Ecole Normale Supérieure de jeunes filles. Paris, 22-23 octobre 1984, Collection de I'Ecole Normale Supérieure de jeunes filles, 30 , Ecole Normale Supérieure de jeunes filles. Avec le concours du Centre National des Lettres et du Centre National de la Recherche scientifique, Paris, 1986, 358 pp.

Aux origines de l'Etat moderne. Le fonctionnement administratif de la papauté d'Avignon. Actes de la table ronde organisée par l'Ecole française de Rome, avec le concours du CNRS, 
du Conseil général de Vaucluse et de l'Université d'Avignon (Avignon, 23-24 janvier 1988), Collection de I'Ecole française de Rome, 138, Ecole Française de Rome, Palais Farnèse, Rome, 1990, 510 pp.

BALARD, Michel (Textes réunis par; préface de Georges Duby): L'histoire médiévale en France: bilan et perspectives, Société des historiens médiévistes de l'enseignement supérieur, L'Univers historique, Ed. du Seuil, Paris, 1991, 566 pp.

BALARD, Michel (Ed.): Villages et villageois au Moyen Age. Société des historiens médiévistes de l'enseignement supérieur. Publications de la Sorbonne, Paris, 1992, 214 pp.

BALARD, Michel (textes réunis par): Bibliographie de l'histoire médiévale en France (1965-1990), Publications. de la Sorbonne. Société des historiens médiévistes de l'enseignement supérieur, Paris, 1992, 486 pp.

BARRAL I ALTET, Xavier, vid. PARISSE, Michel: Le Roi...

Bibliographie annuelle de l' histoire de France, Centre National de la Recherche Scientifique, Paris, 1953-1994 ( = el volum corresponent a la bibliografia apareguda el 1993 du data d'impressió de 1994, 1090 pp.).

BLANCHARD, Joël (Ed.); postface de Philippe Contamine: Répresentation, pouvoir et royauté à la fin du Moyen Age. Actes du colloque organisé par l'Université du Maine les 25 et 26 mars 1994, Picard, Paris, 1995, 340 pp.

BLOCKMANS, Wim et GENET, Jean-Philippe (Eds): Visions sur le développement des Etats européens. Théories et historiographies de l'Etat moderne. Actes du colloque organisé par la Fondation européenne de la science et $l^{\prime}$ Ecole française de Rome. Rome, 18-31 mars 1990, Collection de I'Ecole Française de Rome, 171, Ecole Française de Rome. Palais Farnèse, Rome, 1993, 336 pp.
BOUREAU, Alain et INGERFLOM, Sergio (publié sous la direction de): La Royauté sacre dans le monde chrétien (Colloque de Royaumont, mars 1989), L'Histoire et ses représentations, 3, Editions de 1'Ecole des hautes études en sciences sociales, Paris, 1992, 165 pp.

BOURIN, Monique (Ed.): Villes, bonnes villes, cités et capitales. Etudes d'histoire urbaine (XIIe-XVIIIe siècle) offertes à Bernard Chevalier, Tours, 1989, 419 pp.

BULST, Neithard et GENET, Jean-Philippe (Eds): La Ville, la bourgeoisie et la genèse de l'état moderne (XIIe-XVIIIe siècles). Actes du colloque de Bielefeld (29 novembre - ler décembre 1985), Centre National de la Recherche Scientifique, Paris, 1988, 354 pp.

BURGUIERE, André et REVEL, Jacques (Dir.): Histoire de la France. [1] L'Etat et les pouvoirs (dirigée par Jacques Le Goff). [2] $L$ 'espace français (dirigée par Jacques Revel). [3] Les conflits (dirigée par Jacques Julliard). [4] Les formes de la culture (dirigée par André Burguière)., Editions du Seuil, Paris, [1-2] 1989; [3] 1990; [4] 1993, 653, 669, 669, 601 pp. respect.

BURNS, James Henderson (Dir.): Histoire de la pensée politique médiévale (350-1450), collection Leviathan, Presses Universitaires de France, Paris, 1993 ( $1^{*}$ edició en anglès, 1988), 769 pp.

CAUCHIES, Jean-Marie (Dir.): Institutions et pouvoirs dans les anciens pays bourguignons. Rencontres de Rotterdam, sept. 1983, Centre européen d'études bourguignonnes (XIVe-XVIe siècles), Bâle, 1984, XIV + 113 pp.

CONTAMINE, Philippe, vid. CHEVALIER, Bernard: La France...

CONTAMINE, Philippe (Ed.): L'Etat et les Aristocraties (France, Angleterre, Ecosse) XIle-XVIIe siecle. Actes de la table ronde organisée par le Centre National de la Recher- 
che Scientifique. Maison française d'Oxford 26 et 27 septembre 1986. Presses de I'Ecole Normale Supérieure, Paris, 1989, 394 pp.

COULET, Noël et GENET, Jean-Philippe (Ed.): L'Etat moderne: le droit, l'espace et les formes de l'état. Actes du colloque tenu da la Baume Les Aix, 11-12 octobre 1984, Centre National de la Recherche Scientifique. Centre Régional de publications de Paris, Paris, 1990. $236 \mathrm{pp}$.

Culture et idéologie dans la genèse de l'Etat moderne. Actes de la table ronde organisée par le Centre national de la recherche scientifique et l'Ecole française de Rome. Rome, 15-17 octobre 1984, Collection de I'Ecole française de Rome, 82, Ecole française de Rome. Palais Farnèse, Rome, 1985, VI-528 pp.

CHEVALIER, Bernard et CONTAMINE, Philippe (Eds.): La France de la fin du XVe siècle. Renouveau et apogée. Economie, pouvoirs, arts, culture et conscience nationales, Centre National de la Recherche Scientifique, Paris, 1985, 352 pp.

DUFOURNET, Jean; FIORATO, Adeline et REDONDO, Augustin (études réunies par): Le pouvoir monarchique et ses supports idéologiques aux XIVe-XVIIe siècles, Publications de la Sorbonne Nouvelle, Paris, 1990, 282 pp.

Eglises et pouvoir politique. Actes des journées internationales d'histoire du droit d'Angers. 30 mai - ler juin 1985, Université d'Angers. Presses de l'Université, Angers, 1987, 478 pp.

Etat et pouvoir. La réception des idéologies dans le Midi (Actes du colloque de l'Association française des historiens des idées politiques, Toulouse, 1982), Presses Universitaires d'Aix-Marseille, Aix-en-Provence, 1984, 203 pp.

Etat et pouvoir: réception des idéologies dans le Midi, l'Antiquité et les temps modernes. Actes du colloque de l'Association française des historiens des idées politiques, Lyon, 19-21 septembre 1985, Collection Histoire des idées politiques, 4, Presses universitaires d'Aix-Marseille, Aix-en-Provence, 1986, 260 pp.

FIORATO, Adeline, vid. DUFOURNET, Jean: Le pouvoir...

Genèse de l'Etat moderne en Méditerranée. Approches historique et anthropologique des pratiques et des représentations. Actes des tables rondes internationales tenues à Paris les 24,25 et 26 septembre 1987 et les 18 et 19 mars 1988, Collection de I'Ecole française de Rome, 168, Ecole Française de Rome. Palais Farnèse. Avec le concours du Centre National de la Recherche Scientifique, Rome, 1993, 476 pp.

GENET, Jean-Philippe et LE MENE, Michel (Eds): Genèse de l'État Moderne. Prélèvement et redistribution. Actes du Colloque de Fontevraud, 1984, Centre National de la Recherche Scientifique, Paris, 1987, 250 pp.

GENET, Jean-Philippe (Ed.): L'historiographie médiévale en Europe. Actes du colloque organisé par la Fondation européenne de la science au Centre de Recherches historiques et juridiques de l'Université Paris I du 29 mars au ler avril 1989. Centre National de la Recherche Scientifique, Paris, 1991, 342 pp.

GENET, Jean-Philippe (Ed.): L 'Etat moderne: genèse. Bilans et perspectives. Actes du Colloque tenu au CNRS a Paris les 19-20 septembre 1989. Centre National de la Recherche scientifique, Paris, 1990, 352 pp.

GENET, Jean-Philippe et VINCENT, Bernard (Eds): Etat et Eglise dans la genèse de l'état moderne. Actes du colloque organisé par le Centre National de la Recherche Scientifique et la Casa de Velázquez. Madrid, 30 novembre et ler décembre 1984, Bibliothèque de la Casa de Velázquez, 1, Casa de Velázquez, Madrid, 1986, 312 pp.

GENET, Jean-Philippe, vid. BLOCKMANS, Wim: Visions... 
GENET, Jean-Philippe, vid. COULET, Noël: L'Etat...

GENET, Jean-Philippe, vid. BULST, Neithard: La Ville...

GOURON, André et RIGAUDIERE, Albert (Dir.): Renaissance du pouvoir législatif et genèse de l'Etat, Institut d'Histoire du droit écrit. Pub. de la Société $d$ 'Histoire du Droit et des institutions des anciens pays de droit écrit, Montpellier, 1988, 281 pp.

GUICHARD, P.; LORCIN, M.-T.; POISSON, J.-M. et RUBELLIN, M. (études rassemblées par): Papauté, Monachismes et Théories politiques. I. Le pouvoir et l'institution ecclésiale; II. Les Eglises locales. Etudes d'histoire médiévale offertes à Marcel Pacaut, Collection d'histoire et d'archéologie médiévales. 1 , Centre Interuniversitaire $d^{\prime}$ Histoire et $d^{\prime} \mathrm{Ar}$ chéologie Médiévales et Presses universitaires de Lyon, Lyon, 1994, 856 pp. (paginació seguida).

GY, Pierre-Marie (Ed.): Guillaume Durand, évêque de Mende (1230-1296). (Actes de la table ronde du CNRS de Mende, mai 1990), CNRS, Paris, 1992, 242 pp.

HAMON, Léo et LOBRICHON, Guy (Eds.): L'élection du chef de l'Etat en France. De Hugues Capet à nos jours. Entretiens d'Auxerre 1987, Entretiens d'Auxerre, Beauchesne, Paris, 1988, 241 pp.

HERMANN, Christian (coordination): Le premier àge de l'Etat en Espagne (1450-1700), Collection de la maison des pays ibériques, 41, Centre National de la Recherche Scientifique, Paris, 1989, 414 pp.

Idéologie et propagande en France. Colloque organisé par l'Institut d'histoire et de civilisation française de l'université de Haiffa, 1984. Picard, Paris, 1987, 236 pp.

INGERFLOM, Sergio, vid. BOUREAU, Alain: La Royauté...
IOGNA-PRAT, D. et PICARD, J.-C. (études réunies par): Religion et culture autour de l'an mil. Royaume capétien et Lotharingie. Actes du colloque Hugues Capet 987-1987. La France de l'an Mil, Picard, Paris, 1990, 350 pp.

KRYNEN, Jacques et RIGAUDIERE, Albert (Dir.): Droits savants et pratiques françaises du pouvoir (XIe-XVe siècles), Presses Universitaires de Bordeaux, Bordeaux, 1992, 316 pp.

La France de la fin du XVe siècle, renouveau et apogée: économie, pouvoirs, arts, culture et conscience nationales. Colloque international de Tours, Centre d'Etudes supérieures de la Renaissance, 3-6 octobre 1983, Centre National de la Recherche Scientifique, Paris, 1985 , $\mathrm{X}+352 \mathrm{pp}$.

La monarchie absolutiste et l'histoire en France. Théories du pouvoir, propagandes monarchiques et mythologies nationales. Colloque tenu en Sorbonne les 26-27 mai 1986, Mythes, Critique et Histoire, Presses de I'Université de Paris-Sorbonne, Paris, 1987, 234 $\mathrm{pp}$.

La France de l'an Mil [Colloques Paris, Senlis, Auxerre, Barcelone, Metz], Editions du Seuil, Paris, 1990, 436 pp.

La "France anglaise" au Moyen Age (Actes du CXIe Congrès national des Sociétés savantes, Poitiers, 1986), Section d'histoire médiévale et de philologie, tome 1, Comité des travaux historiques et scientifiques, Paris, 1988, 586 pp.

LE GOFF, Jacques et NORA, Pierre (Dir.): Faire de l'histoire. I. Nouveaux problèmes; II. Nouvelles approches; III. Nouveaux objets., Gallimard, Paris, 1986, 310, 334, 376. pp.

Le roi, le marchand et le sel. Actes de la Table ronde l'impôt du sel en Europe, XIIIe-XVIIIe siècles, saline royale d'Arc-et-Senans 23-25 septembre 1986, Presses Universitaires de Lille, Lille, 1987, 376 pp. 
LE ROY LADURIE, Emmanuel (Dir.): Les monurchies, Centre d analyse comparative des systèmes politiques, Presses Universitaires de France, Paris, 1986, 328 pp.

LE MENE, Michel, vid. GENET, Jean-Philippe: Genèse...

Le Sacre des rois. Actes du colloque international d'histoire sur les sacres et couronnements royaux, 9-12 octobre, Reims 1975, Les Belles lettres, Paris, 1985, 350 pp.

Le sacre, à propos d'un millénaire 987-1987, Ministère de la Culture et de la Communication. Archives nationales. Musée de l'Histoire de France, Paris, 1987, 70 pp.

Lectures médiévales de Virgile. Actes du Colloque organisé par l'Ecole française de Rome. Rome, 25-28 octobre 1982, Ecole française de Rome, Rome, 1985, 443 pp.

Les sociétés méridionales autour de l'an Mil. Répertoire des sources et documents commentés, Centre National de la Recherche Scientifique, Paris, 1992, 477 pp.

Les Robertiens-Capétiens du IXe au XXe siècle. Actes du Colloque du millénaire capétien, Compiègne, 30-31 mai 1987, "Bulletin de la Société d'historique de Compiègne", Compiègne, 30, 1988, pp. 3-236.

Les origines des libertés urbaines. Actes du $16 e$ Congrès des historiens médiévistes de l'enseignement supérieur, Rouen, 7-8 juin 1985, Publications de l'Université de Rouen, Rouen, 1990, 346 pp.

Les Princes et le pouvoir au Moyen Age: XXIIIe Congrès de la Société des historiens médiévistes de l'enseignement supérieur. Brest, mai 1992, Publications de la Sorbonne, Paris, 1993, 330 pp.

Les pouvoirs de commandement (tome 1). Actes du 105e Congrès national des Sociétés savan- tes, Comité des Travaux Historiques et Scientifiques, Paris, 1984, 232 pp.

LEVILLAIN, Philippe (Dir.): Dictionnaire historique de la Papauté, Fayard, Paris, 1994, $1776 \mathrm{pp}$.

Libertés locales et Vie municipale en Rouerge, Languedoc et Roussillon, Actes 59e Congrès Fédération histoire Languedoc méditerranéen Roussillon, Millau 1987, F.H.L.M.R., Montpellier, 1988, 274 pp.

LOBRICHON, Guy, vid. RICHE, Pierre: Le Moyen-Age...

LOBRICHON, Guy, vid. HAMON, Léo: L'élection...

LORCIN, M.-T., vid. GUICHARD, P.: Papauté...

$L$ 'administration locale et le pouvoir central en France et Russie (XIIIe-XVe siècles) [Colloque, Paris, septembre 1989], Comité français des Sciences historiques, Paris, 1990, 175 pp.

Media in Francia. Recueil de Mélanges offert à Karl Ferdinand Werner à l'occasion de son 65 anniversaire par ses amis et collègues français, Maulévrier, 1989, XVI+559 pp.

NORA, Pierre (sous la direction de): Les lieux de mémoire. Tome I: La République; Tome II: La Nation (vols. 1, 2 et 3); Tome III: Les France (vols. 1, 2 et 3), Bibliothèque illustrée des histoires, Gallimard, Paris, 1984-1992, I, XLII +674 pp.; II-1, XXI+610 pp.; II-2, 662 pp.; II-3, 667 pp.; III-1, 988 pp; III-2, 988 pp.; III-3, 1034 pp.

NORA, Pierre, vid. LE GOFF, Jacques: Faire...

PARISSE, Michel et BARRAL I ALTET, Xavier (Etudes réunies par): Le Roi de France et son royaume autour de l'an Mil. Actes du colloque Huges Capet 987-1987. La France de 
l'an Mil. Paris-Senlis, 22-25 juin 1987, Picard, Paris, 1992, 255 pp.

PICARD, J.-C., vid. IOGNA-PRAT, D: Religion...

PINET, Marcel (Dir.); RICHE, Pierre; BOURNAZEL, Eric; AUTRAND, Françoise: Histoire de la Fonction Publique en France. Tome I: des origines au XV siècle, Nouvelle Librairie de France. G.-V. Labat, Paris, 1993, 486 pp.

POISSON, J.-M., vid. GUICHARD, P.: Papauté...

PONS, Nicole (Ed.): "L'Honneur de la Couronne de France". Quatre libelles contre les Anglais (vers 1418 - vers 1429), Klincksieck, Paris, 1990, 220 pp.

Pouvoirs et contrôles socio-politiques (Razo. Cahiers du Centre d'études médiévales de Nice, 9), Nice, 1989.

Pouvoirs et libertés au temps des premiers Capétiens, Maulévrier, 1992, 329 pp.

REDONDO, Augustin, vid. DUFOURNET, Jean: Le pouvoir...

Réflexions idéologiques sur l'Etat, aspects de la pensée politique méditerranéenne, collection $d$ 'histoire des idées politiques, Presses Universitaires d'Aix-Marseille, Aix-en-Provence, 1987, 359 pp.

REMOND, René (Dir.): Pour une histoire politique, Ed. du Seuil, Paris, 1988, 399 pp.
REVEL, Jacques, vid. BURGUIERE, André: Histoire...

RIALS, Stéphane (Dir.): Le miracle capétien, Ed. Perrin, Paris, 1987, 402 pp.

RIALS, Stéphane (Dir.): Le Droit des Modernes (XIVe-XVIIIe siècles), Travaux et recherches Panthéon-Assas Paris II, Librairie Générale de Droit et de Jurisprudence, Paris, 1994, $230 \mathrm{pp}$.

RICHE, Pierre et LOBRICHON, Guy (Dir.): Le Moyen-Age et la Bible, Beauchesne, Paris, $1984,639 \mathrm{pp}$.

RIGAUDIERE, Albert, vid. KRYNEN, Jacques: Droits...

RIGAUDIERE, Albert, vid. GOURON, André: Renaissance...

RUBELliN, M., vid. GUICHARD, P.: Papauté...

SOUFFRIN, Pierre (Ed.): Nicolas Oresme. Tradition et innovation chez un intellectuel du XIVe siècle, Les Belles Lettres, Paris, 1988, $248 \mathrm{pp}$.

Théologie et droit dans la science politique de l'Etat moderne. Actes de la table ronde organisée par l'Ecole française de Rome avec le concours du CNRS, Rome, 12-14 novembre 1987, Collection de I'Ecole française de Rome, 147, Ecole Française de Rome, Palais Farnèse, Rome, 1991, 398 pp.

VINCENT, Bernard, vid. GENET,Jean-Philippe: Etat et Eglise.. 


\section{RÉSUMÉ}

Cet article propose de relancer les travaux d'histoire politique pour comprendre la nature du pouvoir politique au Moyen Age et sa pratique, sans que ce propos implique d'avancer vers le fractionnement de la connaissance historique. On revendique le rôle de I'histoire du droit dans la renovation de cette histoire politique et on met l'emphase sur le besoin d'approximations pluridisciplinaires pour aborder le problème du pouvoir. Il est proposé comme modèle quelque chose de semblable au projet du CNRS français entre les années 1985 et 1988 sous la devise "Genèse de l'Etat Moderne" et sa continuation par I'European Science Foundation sous le titre "The Origin of the Modern State" entre les années 1988 et 1992. L'auteur a recueilli la bibliographie parue entre les années 1984 et 1994 en langue française sur 1 ' histoire politique et juridique, concrètement tout ce que, selon le critère du compilateur, faisait référence aux origines de l'Etat et à la formation du pouvoir politique en France ou en Europe en général du Vème au XVème siècles.

\section{SUMMARY}

Without seeking to compartmentalize different areas of historical knowledge, this article aims to promote studies of political history in an attempt to understand the nature and practice of political power in the Middle Ages. We stress the role of the history of law in this effort to renew the history of politics, and underline the need for multidisciplinary approaches to the problem of power. As our model we propose something similar to the project set up by the French CNRS between 1985 and 1988 entitled "Genèse de l'État Moderne" and its follow-up, "The Origin of the Modern State" run by the European Science Foundation between 1988 and 1992 . We record the bibliography published in French between 1984 and 1994 on political and legal history, especially texts which in the opinion of the compiler refer to the origins of the state and the formation of political power in France or in Europe in general between the fifth and fifteenth centuries. 